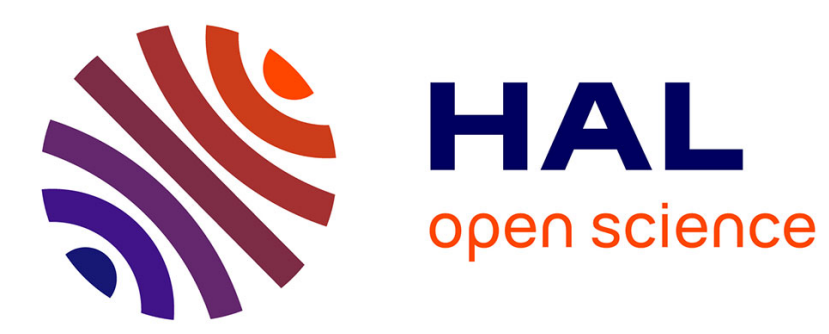

\title{
The effect of an organic pentasulfide EP additive in turning and milling operations
}

Clotilde Minfray, Guillaume Fromentin, Aleksandra Bierla, Jean-Michel Martin, Thierry Le Mogne

\section{To cite this version:}

Clotilde Minfray, Guillaume Fromentin, Aleksandra Bierla, Jean-Michel Martin, Thierry Le Mogne. The effect of an organic pentasulfide EP additive in turning and milling operations. The effect of an organic pentasulfide EP additive in turning and milling operations, 2014, 317 (1-2), pp.129-140. hal-01022909

\section{HAL Id: hal-01022909 \\ https://hal.science/hal-01022909}

Submitted on 11 Jul 2014

HAL is a multi-disciplinary open access archive for the deposit and dissemination of scientific research documents, whether they are published or not. The documents may come from teaching and research institutions in France or abroad, or from public or private research centers.
L'archive ouverte pluridisciplinaire HAL, est destinée au dépôt et à la diffusion de documents scientifiques de niveau recherche, publiés ou non, émanant des établissements d'enseignement et de recherche français ou étrangers, des laboratoires publics ou privés. 


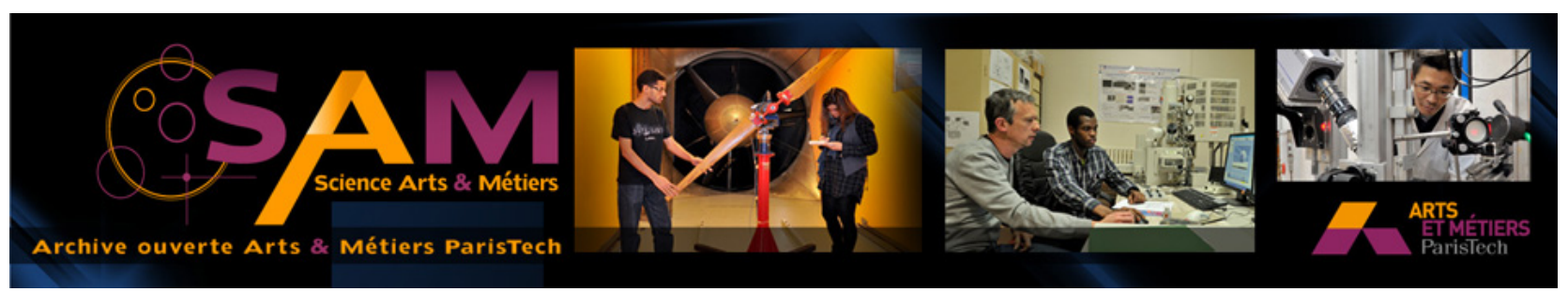

\section{Science Arts \& Métiers (SAM)}

is an open access repository that collects the work of Arts et Métiers ParisTech researchers and makes it freely available over the web where possible.

This is an author-deposited version published in: http://sam.ensam.eu

Handle ID: .http://hdl.handle.net/10985/8344

\section{To cite this version :}

Clotilde MINFRAY, Guillaume FROMENTIN, Aleksandra BIERLA, Jean-Michel MARTIN, Thierry LE MOGNE - The effect of an organic pentasulfide EP additive in turning and milling operations The effect of an organic pentasulfide EP additive in turning and milling operations - Vol. $317, \mathrm{n}^{\circ} 1$ 2, p.129-140 - 2014 


\section{The effect of an organic pentasulfide EP additive in turning and milling}

\section{operations}

Clotilde MINFRAY ${ }^{\mathrm{a}}$, Guillaume FROMENTIN ${ }^{\mathrm{b}}$, Aleksandra BIERLA ${ }^{\mathrm{b}}$, Jean Michel MARTIN ${ }^{\mathrm{a}}$, Thierry Le MOGNE ${ }^{\mathrm{a}}$

aUniversité de Lyon, Ecole Centrale de Lyon, LTDS, France UMR 5513

${ }^{\mathrm{b}}$ Arts et Métiers ParisTech Cluny, LaBoMaP, France

\section{Corresponding Author:}

Clotilde MINFRAY

clotilde.minfray@ec-lyon.fr

Fax: +33478433383

Tel: +33472186336

\section{Abstract:}

Because a cutting fluid could be equally used for different cutting operations, this study proposed to investigate the behavior of a well-known extreme-pressure additive (pentasulfide) in both turning and milling operations of a steel workpiece. The experimental approach is based on the coupling of mechanical tests (turning, milling, and tribological tests) with physico-chemical characterizations (Auger Electron Spectroscopy and X-Ray Photoelectron Spectroscopy) of the friction surfaces (chip and tool). In the case of milling, it was shown that the presence of a pentasulfide additive has a beneficial effect on the specific cutting energy $\left(\mathrm{k}_{c}\right)$ and flank wear $\left(\mathrm{V}_{\mathrm{b}}\right)$. These results are correlated with the presence of iron sulfides ( $\mathrm{FeS}$ and $\mathrm{FeS}_{2}$ ) on the flank face of the cutter mill and on the chip face in contact with the mill. No such additive effects are found in case of turning. A lubrication model is proposed for the case of milling based on an indirect lubrication of the tool/workpiece and tool/chip contacts due to the transfer of iron and its 
reaction with sulfur compounds to produce iron sulfides. Because milling is a discontinuous cutting process, this lubrication mechanism is much more efficient than that observed in turning. Indeed, the tool faces are re-fed iron sulfides each time they leave the workpiece.

Keywords: EP sulfur additives - turning - milling - cutting fluid - Physico-chemical analyses (XPS and AES)

\section{$\underline{1}$ INTRODUCTION}

When performing severe cutting operations, such as turning and milling, a cutting fluid is used for different reasons. First, it contributes to chip evacuation. Second, due to its coolant capacity, the fluid plays an important role in the removal of heat from the contacts. Another reason to use a fluid is to improve the tribological behavior of the different contacts (tool rake face/chip and tool flank face/workpiece). Finally, the fluid is considered based on its lubricating ability obtained due to the additives it contains. Because of European regulations, the use of chlorinated or leaded compounds is no longer allowed. Sulfur additives, which are well known for their extremepressure properties, remain good candidates but need to be formulated with a very low concentration of sulfur. The development of efficient cutting fluids compatible with environmental regulations is the actual goal of lubricant manufacturers. To reach that objective, a better understanding of the action mechanism of sulfur-containing additives for different cutting operations is needed because the same lubricant could be used equally for different cutting operations. 
External turning with a carbide insert and milling with a solid carbide tool are two different machining techniques with different specificities, as described in Fig. 1. During a turning path, the tool is always engaged with the workpiece (continuous cutting), whereas this is not the case for cutting edges during a milling operation (discontinuous cutting). In the latter, the cutting edges enter the material intermittently. The cutting geometries of the tools used in these two machining operations are also different [1]. In turning, the cutting insert has a negative rake angle, and the tool workpiece contact is convex on the flank face. In contrast, the solid milling cutter has a sharp edge and a positive rake angle, and the tool/workpiece contact is concave, which induces an accentuated contact in the flank face compared to turning.

Despite these differences between the turning and milling configurations studied, the two machining techniques both induce chip formation, generate great mechanical stress on the workpiece material and produce a high temperature. During the metal-cutting process, the tool is in contact with the material in two different areas: with the workpiece (tool flank face/workpiece contact) and with the chip (tool rake face/chip contact). Does the lubricant come into these interfaces? This is important to consider regarding the tribological role of the lubricant. As $A$. Mallock mentioned in 1881-82 [2]: "Lubricants seem to act by lessening the friction between the face of the tool and the shaving, and the difficulty is to see how the lubricant gets there". Since then, various authors have proposed lubricant penetration mechanisms in the chip/tool interface considering the following three assumptions:

- The lubricant is in a liquid or gaseous form and fully penetrates the chip-tool interface. If the cutting speed does not exceed $20 \mathrm{~m} / \mathrm{min}$, a lubricant liquid film could be formed inside the contact of the chip with the tool and protect surfaces against adhesion [3]. For higher cutting speeds, it is suggested that the lubricant acts through its vapor form. 


\section{- The lubricant is in a liquid or gaseous form and penetrates partially into the chip-tool}

interface. The lubricant protects the contact surfaces in its range of penetration. Different authors, including Williams, Godlevski and Liu [4-6], have proposed models considering the penetration of liquid or gaseous forms of lubricants in the chip/tool contact through capillaries. The effect of cutting speed has also been discussed [7].

\section{- The lubricant is in a liquid or gaseous form and cannot penetrate into the chip-tool}

interface. This can be encountered under continuous cutting conditions and with very high cutting speeds. According to De Chiffre [8-9], the lubricant flow therefore acts by reducing the contact area between the chip and the tool. Different mechanisms could contribute to this reduction in the contact area. First, the contamination of the tool rake face by the lubricant at the exit of the chip/tool contact could reduce adhesion and thus reduce the contact area. Then, the cooling of the external chip face by the lubricant could contribute to a stronger curvature of the chip, which would also lead to a reduction in the contact area.

It is interesting to note that none of these models takes into account the effect of lubricant additives. Furthermore, it would be necessary to know if discontinuous cutting in milling affects the lubrication process, especially because cutting fluids are actually not really optimized specifically for a milling or a turning application. Additionally, if the cutting continuity affects the lubrication effect, the model of lubricant penetration mechanisms should be reformulated.

In a previous work [1], different sulfur-based molecules have been tested in milling operations. The molecule of interest in this work will be a pentasulfide compound because it has shown good tribological properties in milling.

Thus, the aims of this work were the following: 
(1) To compare the efficiency of the same cutting fluid containing a pentasulfide additive in both turning and milling operations.

(2) To understand the possible action mechanism of this molecule in both machining techniques.

\section{$\underline{2}$ MATERIALS AND METHODS}

The originality of the experimental methodology proposed here is the coupling of both mechanical and physico-chemical experiments: mechanical tests, such as 3D turning, milling and tribological tests, as well as physico-chemical characterizations (XPS and AES) of the different friction surfaces are carried out.

For the machining experiments, force and wear measurements are performed, and different parameters defined in the ISO standard [10-12] are calculated to quantify the efficiency of the lubricant. These results are then correlated with surface analyses (XPS and AES) of the friction surfaces (tool and chip).

Then, a tribological test is proposed in two different controlled environments (presence of pentasulfide and under Ultra High Vacuum). Even if it is not possible to obtain contact conditions that are exactly identical to those obtained during cutting operations, the objective is to focus on the physico-chemical effect of additives on friction. In-situ analyses of friction wear tracks are carried out to investigate the origin of friction and the wear reduction mechanism.

All materials, lubricants, equipment characteristics and conditions of use are detailed in the following. 


\subsection{Materials and lubricant}

Different steels are used as workpiece materials for machining to adapt to machining test constraints. Information relative to these materials is presented in Table 1 . For the turning test, $25 \mathrm{MnCrMoSiVB} 5$ low-alloy steel is chosen with C45 carbon steel to evaluate the cutting fluid performance under softer conditions. The $42 \mathrm{CrMoV} 4$ low-alloy steel, with a similar hardness to that chosen for turning, is used in the milling experiments.

\begin{tabular}{|l|l|l|l|}
\hline Steel designation & Experiment & Ultimate strength & Metallurgical structure \\
\hline C45 & Turning & $800 \mathrm{MPa}$ & Ferrito-pearlitic \\
\hline $25 \mathrm{MnCrMoSiVB} \mathrm{5}$ & Turning & $1000 \mathrm{MPa}$ & Bainitic \\
& Orthogonal cutting & & \\
\hline 42 CrMoV 4 & Milling & $1080 \mathrm{MPa}$ & Bainitic \\
\hline
\end{tabular}

Table 1: Workpiece material for the machining tests.

Concerning the lubricants, two types of fluids are tested: a pure base oil and the same base oil formulated with a sulfur additive. The base oil, noted PBO, is a chemically non-active paraffinic base oil. The cutting fluid contains an organic pentasulfide, noted ADDS1 in the following, and formulated at a concentration of $1 \% \mathrm{w}$ of sulfur in PBO. This additive was chosen from different sulfur additives based on its good performance in milling applications [1].

\subsection{Settings of turning experiments}

The turning experiments are conducted on a 2-axis CNC lathe. A conventional lubrication system with an external nozzle oriented to the tool rake face and a flow of up to $10 \mathrm{~L} / \mathrm{min}$ is used. A 9121 Kistler (Winthertur, Switzerland) dynamometer is used to measure the cutting forces during machining. This instrument allows the measurement of the $F_{c}, F_{f}$ and $F_{p}$ forces, as defined 
by the standard [10]. The average cutting forces are calculated during steady state conditions. The specific cutting energy $\left(k_{c}\right)$ represents the energy needed to remove a given volume of workpiece material. From the mean cutting force, the specific cutting energy $\left(k_{c}\right)$ is calculated as a function of the cut area $A_{D}$ using Eq. 1.

$$
k_{C}=\frac{F_{C}}{A_{D}}
$$

Two turning configurations are applied to reach different types of mechanical analysis: 3D turning and orthogonal cutting.

\subsubsection{D Turning}

Three-dimensional turning tests, i.e., those using a conventional carbide insert with nose, are used to identify the fluid effect on cutting forces in relation to its possible ability to reduce friction at the interfaces. Axial turning paths are run in cylindrical bars. For these tests, ISO P15 TiN-coated carbide inserts are used. Their designations are Sandvik CNMG 120408 PF 4015. The coating is made of different layers of $\mathrm{Ti}(\mathrm{C}, \mathrm{N}), \mathrm{Al}_{2} \mathrm{O}_{3}$ and $\mathrm{TiN}$ on the top surface. The cutting geometry of these inserts includes a $0.07-\mathrm{mm}$ chamfer, which partially induces a negative rake angle.

In 3D turning, the cut area $\left(A_{D}\right)$ is determined as a function of the feed ( $f$ ) and the depth of cut $\left(a_{p}\right)$, cf. [11], using Eq. 2.

$$
A_{D}=f \cdot a_{p}
$$

Furthermore, wear tests to evaluate the influence of the cutting fluid on tool damage are also practiced to quantify its anti-wear ability. During these tests, the tool flank wear is periodically observed, and the $V_{b}$ criterion, as defined by [12], is measured. For minimizing the time spent on wear experiments, the approach we developed consists of comparing the tool wear after a fixed machining time to evaluate the fluid efficiency in reducing tool damage. 


\subsubsection{Orthogonal cutting}

Orthogonal cutting is a plane cutting configuration that makes experiments and analysis easier. Thus, it is often used for research but rarely in industrial applications. This basic configuration requires that the linear cutting edge be perpendicular to both the direction of the cutting speed $\left(\lambda_{\mathrm{s}}=0^{\circ}\right)$ and to the feed direction $\left(\kappa_{\mathrm{r}}=90^{\circ}\right)$. There are three possibilities to apply orthogonal cutting: the straight turning of a tube, disc facing, and slotting. In the present study, the cutting of a tube is used as a mechanical model of cutting to obtain the force and thus determine the friction coefficient at both the tool/chip interface and the flank contact.

The same materials are needed for these experiments as for 3D turning and for the force measurements. Nevertheless, orthogonal cutting induces only a cutting force $\left(F_{c}\right)$ and a feed force $\left(F_{f}\right)$, i.e., no third component. The width of the cut $(b)$ is defined by the tube thickness, and the uncut chip thickness $(h)$ is constant along the cutting edge and is equal to the feed (f). Under these conditions, the cut area $\left(A_{D}\right)$ in orthogonal cutting is given by Eq. 3 .

$$
A_{D}=h . b
$$

The tool inserts for the orthogonal cutting test are made of uncoated carbide (WC + Co binder) with a zero rake angle and a $25-\mu \mathrm{m}$ edge radius $\left(r_{\beta}\right)$. Their designation is ARNO CCMW 09T308EN AK10.

\subsection{Milling set-up and experimental procedure}

The milling experiments are performed on a 3-axis CNC milling center, and as with the 3D turning test, there are two objectives. The first is to deduce the effect of the cutting fluid on friction from the analysis of the cutting force and specific energy. The second objective is to quantify the anti-wear properties of the cutting fluid from wear milling tests. 
Uncoated solid carbide cutters (WC + Co binder) of $10 \mathrm{~mm}$ in diameter with three flutes are used for the milling experiment. Their cutting geometry is composed of a $6^{\circ}$ rake angle and a $30^{\circ}$ helix angle with sharp edges. For the milling experiment, the workpieces are immersed in a special box filled with the cutting fluids. The box volume is approximately $2 \mathrm{~L}$, and the fluid temperature is constant during the milling tests.

\subsubsection{Cutting force experiments}

A 9123C3 Kistler rotating dynamometer measures three forces $\left(F_{x}, F_{y}, F_{z}\right)$ and the $T_{z}$ torque during milling. This piezoelectric sensor has sufficient sensitivity and bandwidth for the milling configuration used in this study. As with the turning test, the specific cutting energy $\left(k_{c}\right)$ is considered and is calculated from the cutting power $\left(P_{c}\right)$ and the chip removal rate $(Q)$ as shown in equation (4) and as explained by the ISO 3002-4 standard [10]. The cutting power is obtained from the measured mean torque $\left(T_{z}\right)$ and the spindle speed $(\omega)$, cf. Eq. (5). The chip removal rate (Q) is deduced from the feed rate $\left(\mathrm{V}_{\mathrm{f}}\right)$, the axial depth of the cut $\left(\mathrm{a}_{\mathrm{doc}}\right)$ and the radial depth of the cut $\left(r_{\text {doc }}\right)$, cf. equation (6). These parameters are detailed in the ISO 3002-3 standard [11].

$$
\begin{aligned}
& k_{c}=\frac{P_{C}}{Q} \\
& P_{c}=\omega \cdot<T_{z}> \\
& Q=V_{f} \cdot a_{d o c} \cdot r_{d o c} \cdot \frac{60}{1000}
\end{aligned}
$$

Unfortunately, small differences in micro-cutting geometry may affect the cutting forces. To obtain only the effect of the fluid, dry milling tests are conducted with all cutters. These tests constitute reference values for cutting force comparisons. 


\subsubsection{Wear experiments}

During wear tests, the rotating dynamometer is not used, and a shorter, more rigid tool holder is employed. This eliminates tool vibration, which may affect the wear behavior of the mills during the tests. As with the turning test, the flank wear on a mill is evaluated using the $\mathrm{V}_{\mathrm{b}}$ criterion. The tool life is defined as the machining time when the flank wear is equal to $0.3 \mathrm{~mm}$.

\section{$2.4 \quad$ Tribological tests}

All of the friction tests are conducted in the Environmentally Controlled Tribometer [13]. The friction experiments are carried out under two different atmospheres: UHV $\left(10^{-6} \mathrm{~Pa}\right)$ and with a partial pressure of pentasulfide of $10 \mathrm{~Pa}$. A pin-on-flat contact is used (pin radius $=1.5 \mathrm{~mm}$ ). The friction tests are performed at $500^{\circ} \mathrm{C}$ with a normal load of $1 \mathrm{~N}$, which corresponds to a maximum Hertzian contact pressure of $1.5 \mathrm{GPa}$. The stroke length is $1 \mathrm{~mm}$, and the sliding speed is $3 \mathrm{~mm} / \mathrm{s}$. The flat is composed of C45 steel, and the pin is composed of AISI52100. Both of them are etched by argon ion $\left(\mathrm{Ar}^{+}, 2 \mathrm{kV}, 5 \times 5 \mathrm{~mm}^{2}\right)$ for $1800 \mathrm{~s}$. XPS analyses were performed after etching to confirm that the native iron oxide layer has been removed and that only iron metal $\left(\mathrm{Fe}^{0}\right)$ is present on the samples. At the end of the test, the samples are transferred from the tribological chamber to the analytical chamber without any air exposure to perform the in-situ XPS analyses of the wear tracks.

\subsection{Surfaces and TEM analyses}

The chip and tool friction surfaces are analyzed by XPS and AES. These two techniques can determine the elemental composition of the extreme surfaces. Using XPS, it is also possible to identify the nature of the chemical bonds existing between the different elements and obtain semi-quantitative information by taking into account the peak area and sensitivity factors. The combination of AES and ion etching establishes the elemental composition in depth. 
The XPS analysis is carried out with an Al $\mathrm{K}_{\alpha}$ line excitation source under Ultra-High-Vacuum (UHV) conditions $\left(10^{-6} \mathrm{~Pa}\right)$. The analytical device is also equipped with an electron gun (FEG1000, Field Emission Gun) for AES analysis and a VG EXO5 ion gun for ion etching and depth profiling. The detection is made using a VG ESCALAB 220i spectrometer. This unit is the same one used in [1]. The XPS and AES spectra are recorded and processed using specialized software (Thermo Avantage ${ }^{\circledR}$ ). All XPS features are fitted using a Shirley background and a Lorentzian-to-Gaussian ratio (L/G) of $60 \%$. The Full Width of Half Maximum (FWHM) was maintained equal for each contribution of each photopeak. The relative intensity of the $S_{2 p 1 / 2}$ and the $S_{2 p 3 / 2}$ peaks is $1: 2$. The Scofield sensitivity factors are employed for the determination of atomic percentages.

All chips and tools intended for analysis are washed ultrasonically in a bath of pure $n$-heptane. To avoid modification of the surface and possible shifting of the sulfur peaks, no ion etching was performed before the XPS analyses. The AES analysis is used for obtaining depth profiles of the chips. Their surfaces are etched with $\mathrm{Ar}^{+}$under the following conditions: $2 \mathrm{kV}, 2 \times 2 \mathrm{~mm}^{2}$, and $10^{-4}$ Pa.

The tribofilm obtained on the chip face in contact with the tool rake face is visualized by TEM observations on the FIB cross section. FIB milling is used to prepare a thin cross-section of the chip tribofilm. The TEM observations are performed on a JEOL 2010F. 


\section{$\underline{3}$ EXPERIMENTAL RESULTS}

\subsection{Turning}

\subsubsection{Cylindrical turning}

\section{Turning force experiments}

First, turning 3D experiments under finish conditions ( $f=0.12 \mathrm{~mm} / \mathrm{rev}$ and ap $=0.45 \mathrm{~mm}$ ) are carried out using a carbide insert tool and 25 MnCrMoSiVB 5 workpiece material. Two lubrication conditions are tested: dry turning and turning using the PBO+ADDS1 fluid. In Fig. 2, the effect of the cutting speed $(\mathrm{Vc})$ on the specific cutting force $(\mathrm{Kc})$ is reported for both dry and lubricated conditions. The same conclusion can be drawn from experiments at different feeds: the presence of an additive in the lubricant has no significant effect on Kc. The decrease in Kc with an increase in the cutting speed is commonly explained by a thermal softening of the workpiece material at high cutting speed but may also be related to a reduction in the friction coefficient and to a reduction in the tool/chip contact area. At lower cutting speeds and hence a lower temperature, the $\mathrm{Kc}$ values do not follow the same trend and show some dispersion. The contribution of the friction behavior to $\mathrm{Kc}$ is probably dominant compared to the material softening. A built-up edge could also be formed and could also contribute to this non-monotone behavior. Because low cutting speeds, such as $50 \mathrm{~m} / \mathrm{min}$, are not relevant considering industrial cutting applications, no further investigations were carried out to explain the low Kc values obtained at low cutting speeds.

Then, softer steel is used to examine whether this preliminary conclusion is linked to initial conditions that are too harsh. The same experiments as that mentioned above but with C45 carbon steel are performed, and the same trend is observed: there is no clear effect of the lubricant additives on $K_{c}$ at different cutting speeds $\left(V_{c}\right)$ and feeds $(f)$, as shown in Figs. $3(A)$ and 
3(B). The increase in feed induces a large decrease in $K_{c}$, which is currently obtained in metal cutting. This finding is explained by a decrease in the effective rake angle and appearance of adiabatic shear bands during chip formation as the uncut chip thickness increases.

Rough turning conditions are also tested. Finally, among all of the conditions tested (roughing/finishing, different steels, different $V_{c}$, different $f$ ), it can be concluded that the formulated lubricant has no strong impact on the measurements of cutting forces compared to dry turning. As a consequence, this finding implies that the pentasulfide additive ADDS1 has poor friction-reduction ability under the tested conditions.

\section{Wear experiments}

Flank wear $\left(V_{b}\right)$ is measured by optical observations of the coated carbide inserts after a given cutting time under finish conditions. Four different conditions are tested: two different workpiece materials (C45 and $25 \mathrm{MnCrMoSiVB} \mathrm{5)} \mathrm{and} \mathrm{two} \mathrm{different} \mathrm{lubrication} \mathrm{conditions} \mathrm{(dry} \mathrm{and} \mathrm{with}$ PBO+ADDS1 fluid). The results are presented in Fig. 4. For both materials, the flank wear is slightly smaller when using the lubricant than that obtained under dry conditions. The sensitivity of tool wear to the use of the PBO+ADDS1 cutting fluid is higher when turning the softer steel. A small effect of the pentasulfide additive ADDS1 on wear resistance is thus found here.

\subsubsection{Mechanical model in orthogonal cutting}

An analytical modeling approach was developed to determine the forces and therefore the friction coefficients on both tool faces. For this, the cutting law for orthogonal cutting is used in a manner similar to that described in [14]. As defined in Fig. 5, it is considered that cutting forces in the tangential and normal directions result from the combination of the edge effect on the clearance face (CF) and of a cut effect on the rake face (RF), which is a function of the uncut chip 
thickness (h). As a consequence of these considerations, the cutting law is identified from experimental results at different feeds and is defined by equations (7).

$$
\begin{aligned}
& F_{c=} F_{R F / n}+F_{C F / t}=b \cdot\left(k_{c n} \cdot h+k_{e n}\right) \\
& F_{f=} F_{R F / t}+F_{C F / n}=b \cdot\left(k_{c t} \cdot h+k_{e t}\right)
\end{aligned}
$$

Based on the definition of the model and its assumptions, a macroscopic friction coefficient on the clearance face $\left(\mu_{\mathrm{CF}}\right)$ and on the rake face $\left(\mu_{\mathrm{RF}}\right)$ can be established. These are expressed by equations (8) when the rake angle is null.

$$
\begin{gathered}
\mu_{R F}=\frac{F_{R F / t}}{F_{R F / n}}=\frac{b \cdot k_{c t} \cdot h}{b \cdot k_{c n} \cdot h}=\frac{k_{c t}}{k_{c n}} \\
\mu_{C F}=\frac{F_{C F / t}}{F_{C F / n}}=\frac{b \cdot k_{e t}}{b \cdot k_{e n}}=\frac{k_{e t}}{k_{e n}}
\end{gathered}
$$

A test campaign of orthogonal cutting (straight turning) under finishing conditions $\left(\mathrm{V}_{\mathrm{c}}\right.$ $=200 \mathrm{~m} / \mathrm{min}$, $\mathrm{f}$ variable $0.05-0.175 \mathrm{~mm} / \mathrm{rev}, \mathrm{b}=3 \mathrm{~mm}$ ) is carried out under dry conditions and with the F1 cutting fluid (PBO + ADDS1) on 25 MnCrMoSiVB 5 steel. The results are presented in Table 2 (Experimental identification of coefficient model): the friction coefficient on the rake face $\left(\mu_{\mathrm{RF}}\right)$ is found to be approximately 0.5 for both dry and lubricated conditions, and the friction coefficient on the clearance face ( $\mu_{\mathrm{CF}}$ ) is found to be approximately 0.7 for both lubricated conditions. Thus, this finding confirms once more the inability of the PBO+ADDS1 cutting fluid to reduce friction. The lower friction coefficient value on the rake face compared to the coefficient on the clearance face can be explained by the higher temperature on the $1^{\text {st }}$ zone due to plastic deformation and friction.

To investigate the sensitivity of the cutting forces to the evolution of the two friction coefficients under consideration, an inverse approach is proposed, cf. Table 2 - Cutting force simulation. This method is based on two mechanical models, namely those proposed by Merchant 
[15] and Lee and Shaffer [16], with the addition of an edge effect. For each model, the variations in forces in three cases are studied: i) a reduction in the friction coefficient on the rake face by a factor of two, ii) a reduction in the friction coefficient on the clearance face by a factor of two and, iii) a reduction in the friction coefficient on both the rake and clearance faces by a factor of two. The results show that, taking into account noise and the inherent differences of tools, a reduction by a factor of two in the friction coefficients on both faces are required to obtain any significant reduction in the forces. This corresponds to a huge reduction in the friction coefficient that has little probability of occurring, taking into account the severity of the machining application. Finally, it can be concluded that the sensitivity of the cutting forces $\left(F_{c}\right.$ and $\left.F_{f}\right)$ to the friction coefficients ( $\mu_{\mathrm{RF}}$ and $\mu_{\mathrm{CF}}$ ) is poor and cannot exceed $40 \%$ even if the magnitude of friction is halved on the tool faces.

Finally, practically no effect is found for the EP additives on friction during turning, even if a small effect is found on wear. It seems that the forces are just not sensitive enough to exert an influence on friction (which exists), whereas wear is sensitive to smaller variations in friction stress.

\subsubsection{Surface analyses on turning inserts and on chips}

To investigate the physico-chemical activity of the pentasulfide additive (ADDS1), AES analyses are performed on a turning insert (Fig. 6) and on a chip face in contact with the tool rake face (Fig. 7). The cutting condition details are the following: $V c=50 \mathrm{~m} / \mathrm{min}, f=0.2 \mathrm{~mm} / \mathrm{rev}$ and $\mathrm{a}_{\mathrm{p}}=0.4 \mathrm{~mm}$. The lubricant used is the formulated one (PBO + ADDS1).

\section{AES analyses on turning insert}

The AES spectrum shown in Fig. 6 is obtained on the rake face of the tool at three different positions. The first profile is obtained at the end of the tool/chip contact area. This area is rich in 
carbon and different oxidized compounds. Sulfur is detected and could be under iron (from steel) or titanium (from tool) sulfides. Profile 2 was obtained in the tool/chip contact area. The layer formed here is rich in iron and sulfur and also contains carbon. An AES depth profile is performed to investigate whether the composition of this transferred layer changes with depth. Carbon and oxygen are found only at the extreme surface (contamination), but a significant layer composed mainly of iron and sulfur is observed at greater depth. After more than $1000 \mathrm{~s}$ of argon ion etching, elements characteristic of the tool are detected. Close to the cutting edge (profile 3), almost no sulfur is detected (mostly carbon).

As a consequence, these results show that an iron and sulfur layer (iron sulfide) is found on the tool rake face in the tool/chip contact area.

\section{AES analyses on chip (side in contact with the tool rake face)}

In Fig. 7, the AES profile on the chip surface in contact with the rake face of the tool is shown. The results show the presence of an iron- and sulfur-rich layer on the surface of the chip.

Finally, on the tool rake face and on the chip surface in contact with it, reaction products made of iron (arising from the workpiece material) and sulfur (originating from the pentasulfide additive) are detected.

\subsection{Milling}

\subsubsection{Mechanical and wear results}

The specific cutting energy $\left(k_{c}\right)$ is calculated during the milling test as described in $\$ 2.3$. The workpiece material is a low-alloy steel $42 \mathrm{CrMoV} 4$ with mechanical properties similar to those of 
the material used in the 3D turning tests. The milling trials are performed under the following range of conditions: $V_{c}=60 \mathrm{~m} / \mathrm{min}, f_{z}=0.1 \mathrm{~mm} / \mathrm{rev} / \mathrm{th}$, to $V_{c}=180 \mathrm{~m} / \mathrm{min}, f_{z}=0.3 \mathrm{~mm} / \mathrm{rev} / \mathrm{th}$, with $r_{\text {doc }}=2 \mathrm{~mm}, a_{d o c}=2 \mathrm{~mm}$. The lubrication conditions tested are the following: dry conditions, with pure base oil (PBO) and with cutting fluid containing the base oil and pentasulfide (PBO + ADDS1).

The results of $k_{c}$ as a function of the lubrication type and cutting conditions are shown in Figs. $8(\mathrm{~A})$ and $8(\mathrm{~B})$. The cutting speed and feed have a significant effect, as previously characterized and explained, cf. [1]. At low cutting speeds, i.e., $60 \mathrm{~m} / \mathrm{min}$, the presence of ADDS1 reduces $\mathrm{k}_{\mathrm{c}}$ by $15 \%$ compared to the dry case. For cutting speeds that are threefold higher than this value, no additional specific cutting energy reduction is observed. The use of PBO may have a negative effect on $k_{c}$ at lower cutting speeds, which could be explained by a loss of thermal softening without the beneficial effect of lubrication.

The tool life results are shown in Fig. $8(\mathrm{C})$. The gain obtained using cutting fluid compared to the dry condition is approximately $60 \%$ at lower cutting speeds and is weakly affected by higher cutting speeds; nevertheless, this parameter markedly reduces the tool life (98 $\mathrm{min}$ to $20 \mathrm{~min}$ ). Moreover, the use of $\mathrm{PBO}$ during milling leads to a shorter tool life, and this confirms its inappropriate characteristics on the specific cutting energy. Consequently, the ADDS1 additive would be responsible for the benefits obtained with the PBO+ADDS1 fluid, and its effect on wear resistance is even more significant on the reduction of flank wear $\left(V_{b}\right)$.

\subsubsection{Surface analyses on chips and mill cutters}

Because a significant activity of pentasulfide is found during the milling experiments, physicochemical analyses of both chip surfaces in contact with the tool rake face and the mill cutter surfaces are carried out. 


\section{Chip surface in contact with tool rake face}

A Focused Ion Beam (FIB) sample preparation was carried out on the chip face to visualize the extreme surface of the chip by TEM. The TEM image is shown in Fig. 9(A). Platinum and resin layers are deposited on the sample for the FIB preparation process. A 40- to 70-nm layer is found at the top of the chip. EDS analyses performed in this layer show that it is composed of iron and sulfur (Fig. 9(B)). To more deeply understand the composition of this layer, an AES depth profile and XPS analyses are also performed on the chip (Fig. 10(A) and Fig. 10(B), respectively). The AES depth profile confirmed the TEM observation, i.e., the presence of an iron- and sulfur-rich layer on the chip. As a result of the XPS analyses of the $S_{2 p}$ peak (Fig. 10(B)), it is possible to identify this layer as mainly iron sulfide ( $\mathrm{FeS}$ and $\mathrm{FeS}_{2}$ ) with the presence of non-reacted additive, sulfite and sulfate compounds.

\section{Mill cutter surfaces}

As a result of the XPS analyses on the tool flank and rake faces (Fig. 11), iron sulfides in the form of FeS as well as non-reacted additive and sulfate are also detected. Consequently, a transfer layer made of iron sulfide appears on each of the tool faces.

\subsection{Tribological tests under a controlled environment}

Considering the milling results, a correlation is found between the mechanical observations (force and wear) and the chemical activity of sulfur, i.e., the presence of iron sulfides on both the chip and tool. To investigate a possible correlation between the presence of iron sulfide in the contact and good anti-wear and friction properties, tribological tests are carried out in a pin-onflat tribometer under two different controlled environments (Ultra High Vacuum and in presence of pentasulfide additive). This approach, called gas-phase lubrication, was previously found to be 
representative of real liquid lubrication [17-18]. In-situ XPS analyses are performed at the end of the test on the flat wear tracks to obtain a better understanding of the possible tribochemical phenomena.

\subsubsection{Tribological test results}

It is not possible to obtain conditions using the tribometer used in this study that are same as those achieved during milling or turning. For this reason, taking into account the machine limits, contact conditions are chosen to be as close as possible to those observed during the cutting application. The friction test conditions are the following: a sliding speed of $3 \mathrm{~mm} / \mathrm{s}$, a stroke length of $1 \mathrm{~mm}$, a Hertzian normal pressure of $1.5 \mathrm{GPa}$ and a temperature of $500^{\circ} \mathrm{C}$. The pin is composed of AISI52100 steel, and the flat is composed of C45 steel. Both are etched by argon ion to remove the native iron oxide layer and to obtain iron metal $\left(\mathrm{Fe}^{0}\right)$. During turning and milling, the conditions are so severe that oxygen probably has no access to the contact, and thus, only the iron metal $\left(\mathrm{Fe}^{0}\right)$ of the steel is present in the contact.

The friction coefficients as a function of the number of cycles under UHV at a temperature of $500^{\circ} \mathrm{C}$ and with $10 \mathrm{~Pa}$ of pentasulfide (ADDS1) at a temperature of $500^{\circ} \mathrm{C}$ are shown in Fig. $12(\mathrm{~A})$ and $12(B)$, respectively. Under UHV, this test is difficult to perform as adhesion occurs, which leads to stick-slip phenomena (Fig. 12(A)). However, when introducing $10 \mathrm{~Pa}$ of pentasulfide (ADDS1) to the chamber, the friction coefficient is stable at a value of approximately 0.9 throughout the test. Thus, a strong difference in the tribological behavior of this $\mathrm{Fe}^{0} / \mathrm{Fe}^{0}$ contact is found regarding the environment.

\subsubsection{Surface analyses}

To understand tribochemical phenomena, in-situ XPS analyses of the flat wear track obtained after the experiment with pentasulfide are performed. The presence of both iron and sulfur is 
detected. The analysis of the $S_{2 p}$ spectrum shown in Fig. 13(A) clearly reveals the presence of FeS 2 . This result is surprising at first because the XPS analyses performed in the case of milling find mostly FeS sulfide. To investigate the effect of air exposure on the track composition, the sample is removed from the tribometer, i.e., exposed to air atmosphere, and then re-entered into the apparatus for a second XPS analysis. The XPS analysis after air exposure (Fig. 13(B)) shows that the type of sulfide has changed: there is now mainly FeS with less $\mathrm{FeS}_{2}$.

\section{DISCUSSION}

\section{Analysis related to the ADDS1 additive behavior in turning}

Considering our experimental turning conditions, the results show that the presence of pentasulfide additive in the cutting fluid (PBO+ADDS1) has practically no effect on the specific cutting force and has only a small reduction effect on tool wear. In contrast, additive activity is observed on the tool because a layer made of iron and sulfur is detected (probably iron sulfides). The same type of layer is also found on the chip face in contact with the rake face of the tool. To conclude, a poor additive effect is obtained on cutting forces and wear measurements during turning experiments even if some evidence of additive activity is present. It is thought that the additive reaction takes place after the contact of the tool with the workpiece and that iron may transfer from the workpiece to the tool and may react, after the end of the test, with sulfur species to form iron sulfides. Thus, it would be logical that there is only a small impact on the specific cutting energy and wear. Iron sulfides are known to have interesting properties against wear [19], but the difficulty is to provide these in the contact. During the test, it seems difficult for the lubricant and thus the additive to penetrate directly inside the chip/rake face contact. The third case developed in the introduction ( $\$ 1$ lubricant is under liquid or gaseous phase and cannot penetrate into the chip-tool interface) seems more likely to occur here. However, an indirect 
lubrication occurring between two passes could be considered due to the generation of iron sulfides on the tool before re-engagement in the contact. However, because iron sulfides are progressively worn, this effect could only be transient and thus difficult to detect with our experimental procedure. Furthermore, based on the analysis developed with the 2D force model presented in §3.1.2, the presence of iron sulfides will have a poor effect on the reduction of the friction coefficient inside the contact because the sensitivity of forces to the friction coefficient is poor.

\section{Analysis related to the ADDS1 additive behavior in milling}

For the given milling conditions, the use of a pentasulfide additive is very efficient: a $15 \%$ reduction in the specific cutting energy and a $62 \%$ increase in tool life compared to the dry case. These benefits are correlated with the presence of iron sulfides ( $\mathrm{FeS}$ and traces of $\mathrm{FeS}_{2}$ ) on the chip and tool surfaces. As a consequence, there is a concurrence between the milling test results and the sulfur chemical activity.

\section{Friction tests under controlled atmosphere}

Based on the tribological tests, it can be concluded that the presence of the pentasulfide has a strong effect on the tribological behavior of this interface and is really beneficial compared to the case under UHV. During this tribological test with the pentasulfide, the iron sulfide $\mathrm{FeS}_{2}$ is generated in the flat wear track. This FeS ${ }_{2}$ sulfide form is not stable in contact with open air, where FeS is preferentially found. This can be explained by a possible reaction between $\mathrm{FeS}_{2}$ and $\mathrm{O}_{2}$. The S-S bond is known to be weaker than the Fe-S bond [20] and thus easily oxidized by $\mathrm{O}_{2}$. The following reaction could occur [21]:

$$
\mathrm{FeS}_{2}+\mathrm{O}_{2}(\mathrm{~g}) \rightarrow \mathrm{FeS}+\mathrm{SO}_{2}(\mathrm{~g})
$$


Considering the phase diagram of Fe-S-O [20], it can be observed that, depending on the amount of oxygen and sulfur in the contact, different types of iron sulfides ( $\mathrm{FeS}, \mathrm{FeS}_{2}$ with increasing sulfur concentration) or iron oxides $\left(\mathrm{Fe}_{3} \mathrm{O}_{4}, \mathrm{Fe}_{2} \mathrm{O}_{3}\right.$ with increasing $\mathrm{O}$ concentration) can be generated. The presence of oxygen will interfere negatively with the generation of sulfides. This was noted by different authors [22-23]. Concerning the tribological capacities of $\mathrm{FeS}$ and $\mathrm{FeS}_{2}$, probably both of these compounds are able to reduce wear because their generation reduces the adhesion of $\mathrm{Fe}^{0}-\mathrm{Fe}^{0}$. Concerning the friction properties of both types of sulfides ( $\mathrm{FeS}$ and $\mathrm{FeS}_{2}$ ), some authors suggest a better wear reduction with crystalline FeS because its hexagonal structure could facilitate shearing planes [18-24]. In our case, it is very difficult to make any correlation between the iron sulfide types and specific tribological behavior.

\section{Comparison of turning and milling}

The comparison of the turning and milling results obtained in this study can lead to the conclusion that the pentasulfide additive is efficient in milling in the sense that it allows a signification reduction in wear and friction forces. In contrast, the additive has practically no positive effect in the case of turning. One explanation for these different effects may be proposed based on several points:

First, it is important to note that turning is a continuous cutting process, whereas milling is a discontinuous one. In the latter case, the teeth of the mill cutter enter the workpiece intermittently, whereas the cutting edge is constantly engaged in the workpiece material during a turning path. Furthermore, the sharpness of the mill cutter is better, and there is a concave contact between the tool and workpiece material in milling. Moreover, it is important to mention that we detected transfer material composed of iron and sulfur (iron sulfide) on the tool and on the mill in both cases. 
Based on these facts, a lubrication mechanism is proposed in the case of milling (cf. Fig. 14):

The cutting edges are engaged in the workpiece. Due to the severe conditions, the fluid cannot enter the tooth/chip and tooth/workpiece contacts. However, during this phase, the transfer of iron from both the chip and workpiece to the tool is possible. Because milling is a discontinuous process, the teeth leave the workpiece material. A reaction of metallic transfer with pentasulfide (ADDS1) is possible and would lead to the generation of $\mathrm{FeS}_{2}$ and/or FeS compounds. When a cutting edge is re-engaged in the workpiece, because iron sulfides are present on the tool, they can indeed lubricate the contact.

Thus, the proposed mechanism is an indirect lubrication mechanism through the generation of iron sulfide on the mill cutter. Because milling is a discontinuous process, the teeth are reactivated very often, and thus, the impact of lubrication (anti-wear and friction reduction) is important. In the case of turning, because the contact between the tool and the workpiece is continuous, there is little possibility to provide iron sulfide to the contact (only between two passes). Only a transient effect, hardly detectable, could be expected, and this effect vanishes very quickly. This could explain why the effect of the pentasulfide additive in turning was negligible in our case.

\section{$\underline{5}$ CONCLUSIONS}

The lubrication capacity of an extreme-pressure additive (pentasulfide) in two different machining techniques (turning and milling) is investigated in this study. The main results found are mentioned in the following:

- The effect of the pentasulfide additive on lubricant properties is poor in the case of turning but much more significant in the case of milling. 
- In the case of milling, a correlation is found between the lubricant capacity of the additive (wear and force reductions) and the presence of iron sulfide.

- A milling lubrication mechanism model is proposed based on two important aspects: the transfer of iron sulfide ( $\mathrm{FeS}$ and $\mathrm{FeS}_{2}$ ) from the tool and the discontinuous nature of milling cutting.

In the milling application studied, an effect of lubrication on the specific cutting energy is noted, and this energy mainly results from the tool/chip contact. Evidence from wear tests clearly supports the additive benefit in reducing the flank face damage. Future studies should be conducted to complete the understanding of lubrication mechanisms. In fact, the actions of the additive on the tool flank face and the tool rake face have not been characterized separately, whereas it is known that thermo-mechanical conditions, in terms of pressure, temperature, and sliding speed, are relatively different.

\section{Acknowledgements:}

The authors thank Béatrice VACHER for the TEM experiments, TOTAL Company for supporting this research work, and especially Nicole GENET for her collaboration to this study. 


\section{Bibliography}

[1] A. Bierla, G. Fromentin, C. Minfray, J.M. Martin, T. Le Mogne, N. Genet, Mechanical and physicochemical study of sulfur additives effect in milling of high strength steel, Wear 286-287 (2012) 116-123.

[2] A. Mallock, The action of cutting tools, Proc. R. Soc. Lond., 33 (1881-82) 127-139.

[3] M.E. Merchant, Cutting-fluid action and the wear of cutting tools, Proceedings of the Conference on Lubrication and Wear, Institution of Mechanical Engineers, London (1957) 566-574.

[4] J.A. Williams, The action of lubricants in metal cutting, Journal of Mechanical Engineering Science 19(5) (1977) 202-212.

[5] V.A. Godlevski, Water steam lubrication during machining, Tribologia 162(6) (1998) 11.

[6] J. Liu, R. Han, L. Zhang, H. Guo, Study on lubricating characteristics and tool wear with water vapour as coolant and lubricant in green cutting, Wear 262 (2007) 442-452.

[7] T.H.C. Childs, Friction modelling in metal cutting, Wear 260(3) (2006) 310-318.

[8] L. De Chiffre, Mechanical testing and selection of cutting fluids, Lubrication Engineering 36(1) (1980) 3339.

[9] L. De Chiffre, Mechanics of metal cutting and cutting fluid action, Int. J. Mach. Tool Des. Res. 17(4) (1977) 225-234.

[10] ISO 3002-4 Standard: Basic quantities in cutting and grinding - Part 4: Forces, Energy, Power.

[11] ISO 3002-3 Standard: Basic quantities in cutting and grinding - Part 3: Geometric and Kinematic quantities in cutting.

[12] ISO 8688-2 Standard: Tool life testing in milling - Part 2: End milling.

[13] C. Matta, M.I. De Barros Bouchet, T. Le-Mogne, B. Vacher, J.M. Martin, T. Sagawa, Tribochemistry of tetrahedral hydrogen-free amorphous carbon coatings in the presence of $\mathrm{OH}$-containing lubricants, Lubrication Science 20(2) (2008) 137-149.

[14] Armarego E.J.A., The Unified-Generalised mechanics of cutting approach - a step towards a house of predictive performance models for machining operations, Proc. 3rd CIRP Int. Workshop on modelling of machining operations, Sydney, Australia 2000.

[15] M.E. Merchant, Mechanics of the metal cutting process, J. App. Phys. 16(6) (1945) 318-324.

[16] E.H. Lee, B.W. Shaffer, The theory of plasticity applied to a problem of machining, Trans. ASME J. Appl. Mech. 18(4) (1951) 405-413.

[17] M. Boehm, J.M. Martin, C. Grossiord, T. Le Mogne, Modelling tribochemical reactions of additives by gas-phase lubrication, Tribology Letters. 11 (2001) 83-90. 
[18] J. Tannous, Lubrication par les composes organo-soufrés en phase gazeuse: Approche de la lubrification dans la coupe des métaux, Thesis Ecole Centrale de Lyon 2007 defended decembre 5th 2007, $n^{\circ} 2007-39$.

[19] M.I. De Barros, J. Bouchet, I. Raoult, T. Le Mogne, J.M. Martin, M. Kasrai, Y. Yamada, Friction reduction by metal sulfides in boundary lubrication studied by XPS and XANES analyses, Wear (254) (9) (2003) 863870.

[20] M. Watanabe, M. Sakuma, T. Inaba, Y. Iguchi, Formation and oxydation of sulfides on pure iron and iron oxides, Materials Transaction JIM 41(7) (2000) 865-872.

[21] R. Murphy, D.R. Strongin, Surface reactivity of pyrite and related sulfides, Surface Science Reports 64(1) (2009) 1-45.

[22] M. Tomaru, S. Hironaka, T. Sakurai, Effects of some chemical factors on film failure under EP conditions, Wear 41(1) (1977) 141-155.

[23] D.R. Wheeler, X-ray photoelectron spectroscopic study of surface chemistry of dibenzyl disulfide on steel under mild and severe wear conditions, Wear 47(2) (1978) 243-254.

[24] H. Wang, B. Xu, J. Liu, D. Zhuang, Investigation on friction and wear behaviors of FeS films on L6 steel surface, Applied Surface Science, 252(4) (2005) 1084-109. 


\section{List of figures}

Fig. 1 Milling and turning specificities

Fig. 2 Effect on the specific cutting force of the cutting speed in the case of finishing turning of 25 MnCrMoSiVB 5 steel under dry conditions and with oil (PBO+ADDS1)

Fig. 3 Effect of cutting conditions on the specific cutting force in the case of the preforming turning of C45 steel under dry conditions and with oil (PBO+ADDS1): (A) effect of cutting speed $(V c)$ and $(B)$ effect of feed ( $f$ )

Fig. 4 Flank wear of the tool in the case of the turning of C45 and 25MnCrMoSiVB steels under dry conditions and with oil (PBO+ADDS1)

Fig. 5 Schematic of tool/chip contact and force decomposition on each tool face (rake and clearance faces)

Fig. 6 Turning experiments - AES analyses of the carbide tool (spectrum and AES depth profile)

Fig. 7 Turning experiments - AES analyses of the chip surface in contact with the tool rake face.

Fig. 8 Effect of different lubrication conditions during 42CrMoV4 steel milling: (A) effect of the cutting conditions on the specific cutting energy; (B) effect of the lubrication conditions on the specific cutting energy; and (C) effect on tool life

Fig. 9 Chip obtained after milling with oil PBO+ADDS1: (A) TEM image of FIB cross-section and (B) EDS analyses of the chip surface in contact with the tool rake face

Fig. 10 Chip obtained after milling with oil PBO+ADDS1: (A) AES depth profile and (B) XPS analyses of the chip surface in contact with the tool rake face

Fig. 11 Tool after milling with oil PBO+ADDS1: $(A)$ XPS analyses $\left(S_{2 p}\right.$ peak) on the rake face and (B) XPS analyses ( $S_{2 p}$ peak) of the flank face 
Fig. 12 Friction coefficient as a function of time for a steel-steel pin-on-flat tribotest under controlled environments: (A) $500^{\circ} \mathrm{C}$ and Ultra High Vacuum and (B) $500^{\circ} \mathrm{C}$ and $10 \mathrm{~Pa}$ of pentasulfide

Fig. 13 XPS analyses ( $S_{2 p}$ peak) of flat wear track obtained after friction experiments under controlled environment $\left(500^{\circ} \mathrm{C}\right.$ and $10 \mathrm{~Pa}$ pentasulfide): (A) in-situ analyses and (B) analyses of the same sample after air exposure

Fig. 14 Schematic of proposed lubrication mechanism in the case of milling

Table 1 Workpiece materials used for machining test.

Table 2 Results of mechanical model in orthogonal cutting. 


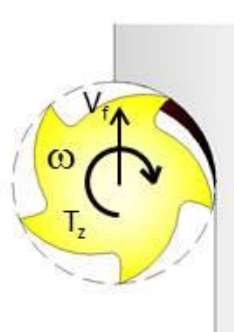

Milling

Discontinuous cutting Concave flank contact Sharp cutting edge Lower cutting speed

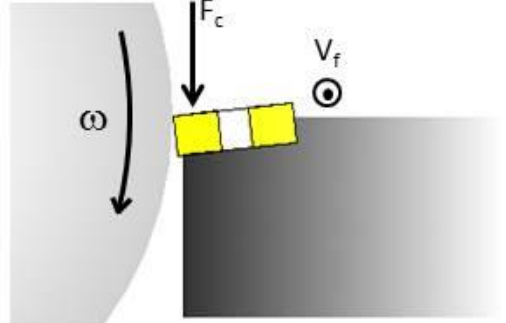

Cylindrical turning Continuous cutting Concave flank contact Chamfered cutting edge Higher cutting speed

Fig. 1 


\begin{tabular}{|c|c|c|c|}
\hline Steel designation & Experiment & Ultimate strength & $\begin{array}{c}\text { Metallurgical } \\
\text { structure }\end{array}$ \\
\hline C45 & Turning & $800 \mathrm{MPa}$ & Ferrito perlitic \\
\hline $25 \mathrm{MnCrMoSiVB} \mathrm{5}$ & Turning & $1000 \mathrm{MPa}$ & Bainitic \\
& Orthogonal cutting & & \\
\hline 42 CrMoV 4 & Milling & $1080 \mathrm{MPa}$ & Bainitic \\
\hline
\end{tabular}

Table 1: workpiece material used for machining test.

Table 1 


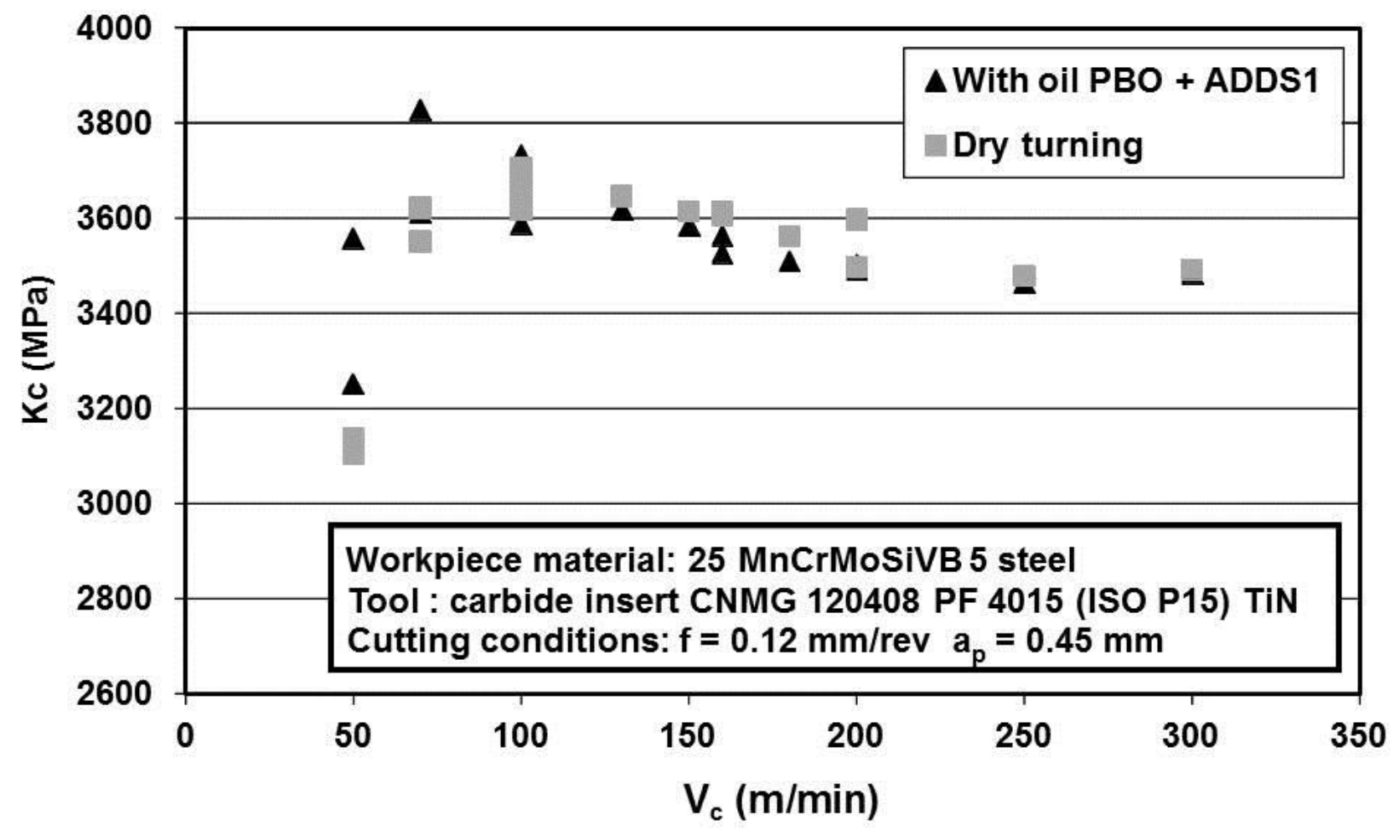

Fig. 2 


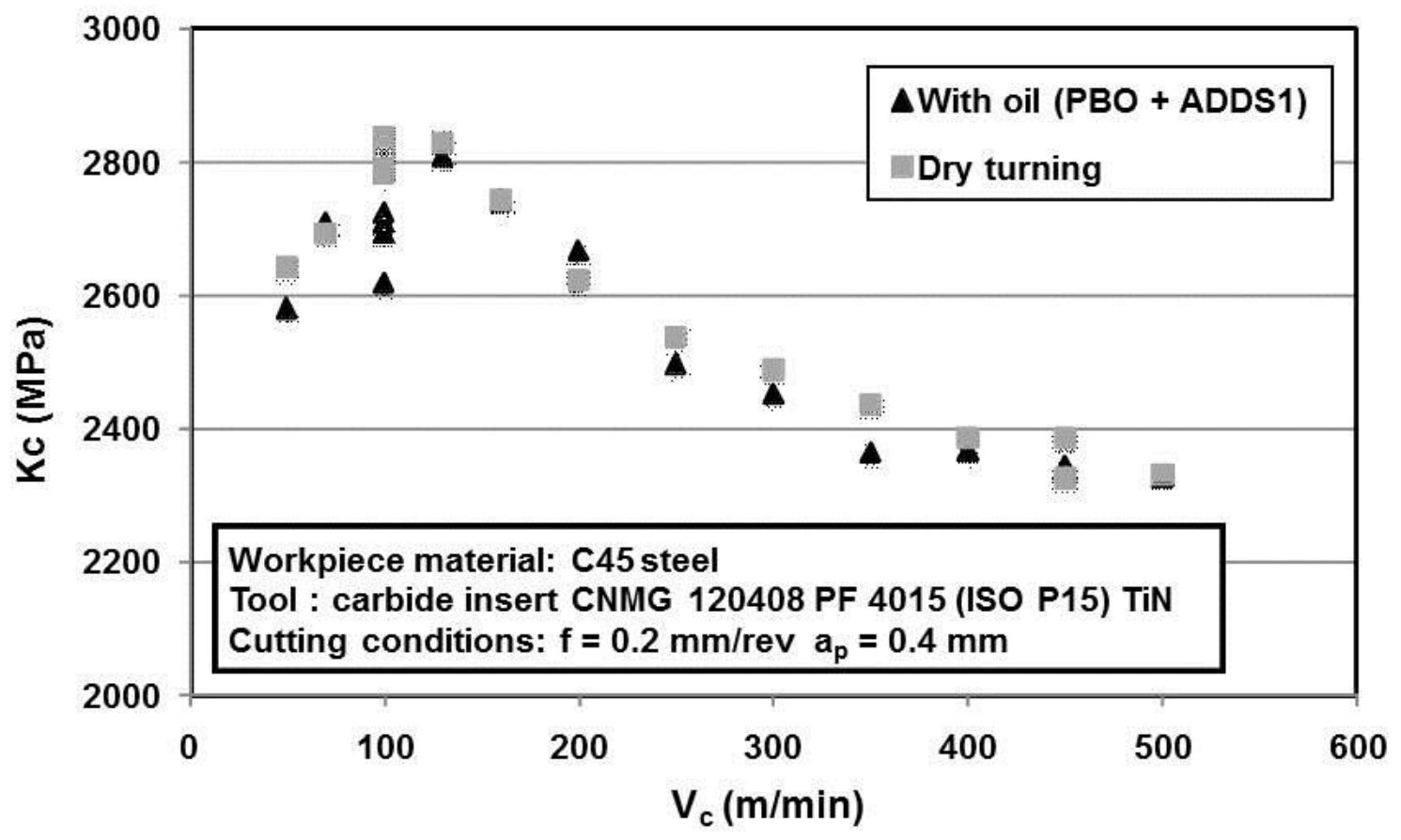

Fig. 3(A) 


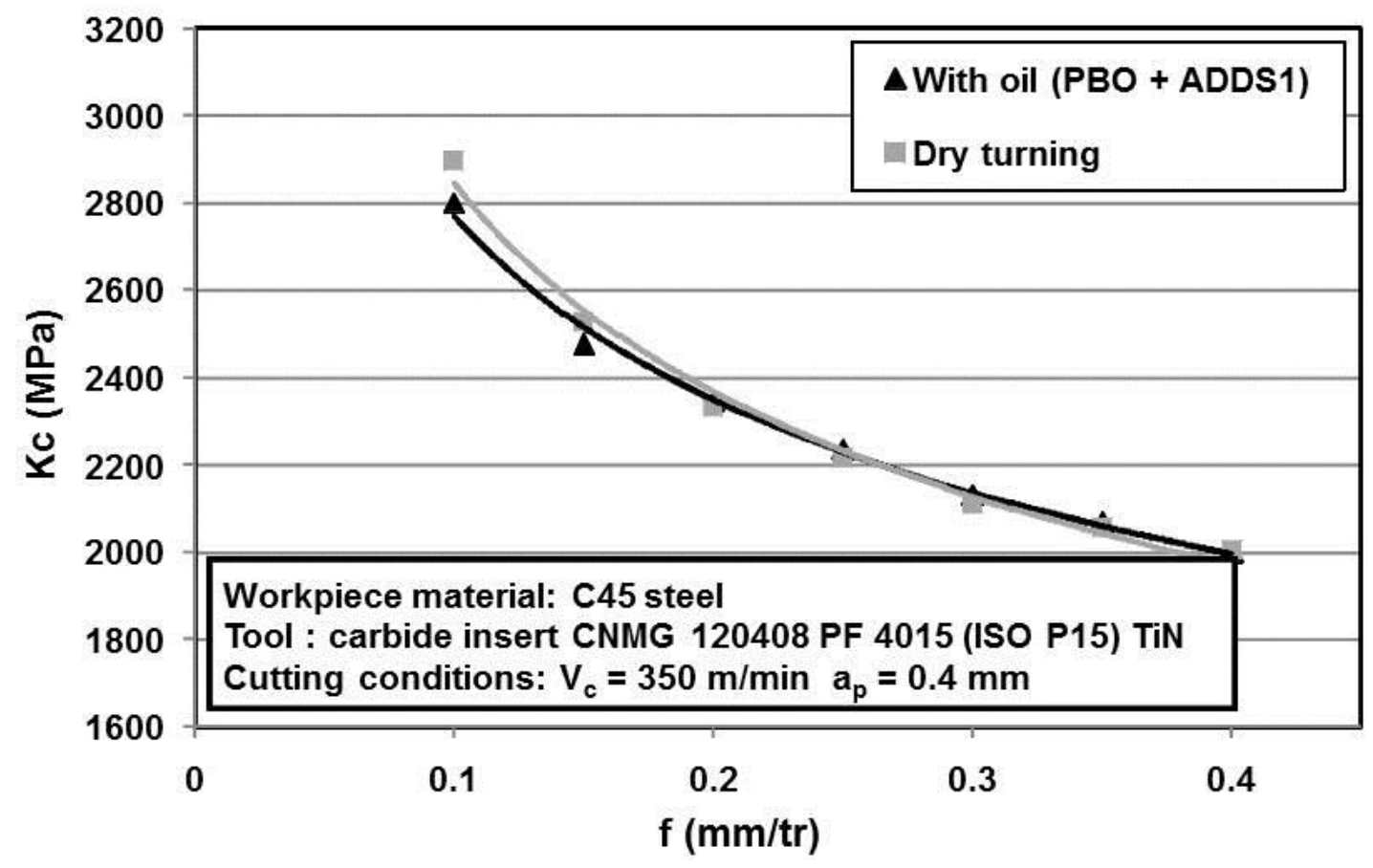

Fig. 3(B) 
Coated carbide insert: CNMG 120408 PF 4015

Workpiece material: $\mathrm{C} 45$ Steel

Cutting conditions: $V_{c}=300 \mathrm{~m} / \mathrm{min}, \mathrm{f}=0.2$

$\mathrm{mm} / \mathrm{rev}, \mathrm{a}_{\mathrm{p}}=0.4 \mathrm{~mm}, \mathrm{t}_{\mathrm{c}}=30 \mathrm{~min}$

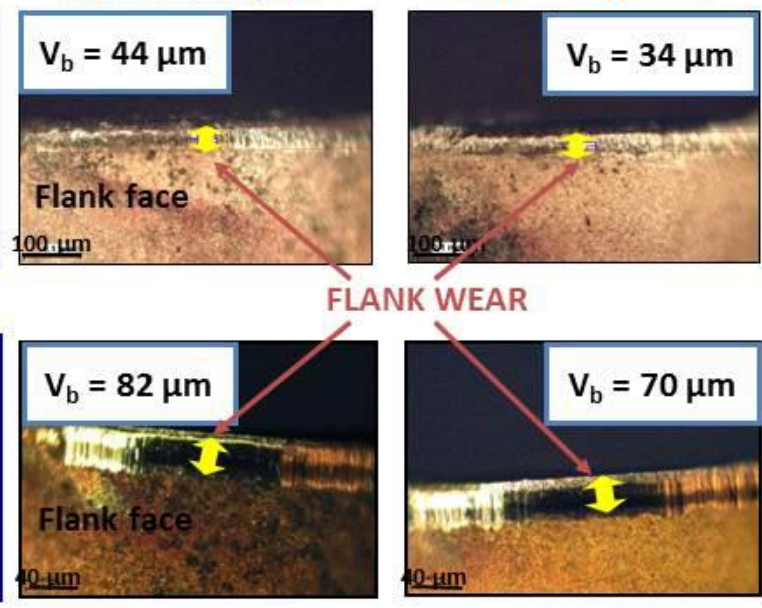

Fig. 4 


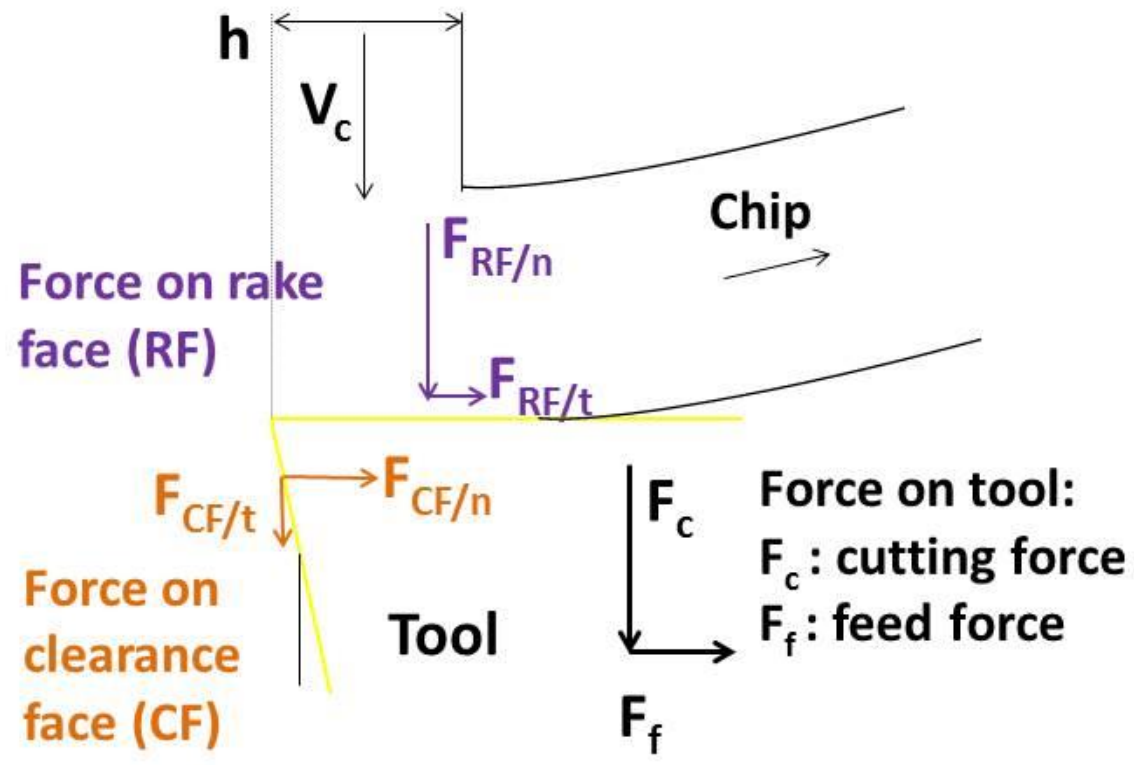

Fig. 5 


\begin{tabular}{|c|c|c|c|c|c|}
\hline $\begin{array}{c}\text { Approach for } \\
\text { orthogonal cutting }\end{array}$ & $\begin{array}{c}\text { Analytical } \\
\text { model for } \\
\text { cutting forces }\end{array}$ & $\boldsymbol{\mu}_{\mathrm{RF}}$ & $\boldsymbol{\mu}_{\mathrm{CF}}$ & $\begin{array}{c}\mathbf{F}_{\mathrm{c}} \\
\text { Variation }\end{array}$ & $\begin{array}{c}\mathbf{F}_{\mathbf{f}} \\
\text { Variation }\end{array}$ \\
\hline $\begin{array}{c}\text { Experimental identification } \\
\text { of model coefficient }\end{array}$ & & $\begin{array}{c}0,5 \\
\text { (dry or } \\
\text { with F1) }\end{array}$ & $\begin{array}{c}0,7 \\
\text { (dry or with } \\
\mathrm{F} 1 \text { ) }\end{array}$ & & \\
\hline Cutting force simulation & Merchant [MER_45] & 0,25 & 0,7 & $\% 16$ & $\% 35$ \\
\cline { 3 - 6 } & & 0,5 & 0,35 & $\% 10$ & No effect \\
\cline { 3 - 6 } & \multirow{2}{*}{$\begin{array}{c}\text { Lee \& Shaffer } \\
\text { [LEE_51] }\end{array}$} & 0,25 & 0,35 & $\% 26$ & $\% 35$ \\
\cline { 3 - 6 } & & 0,5 & 0,7 & $\% 25$ & $\% 38$ \\
\cline { 3 - 6 } & & 0,25 & 0,35 & $\% 35$ & $\% 38$ \\
\hline
\end{tabular}

Table 2 


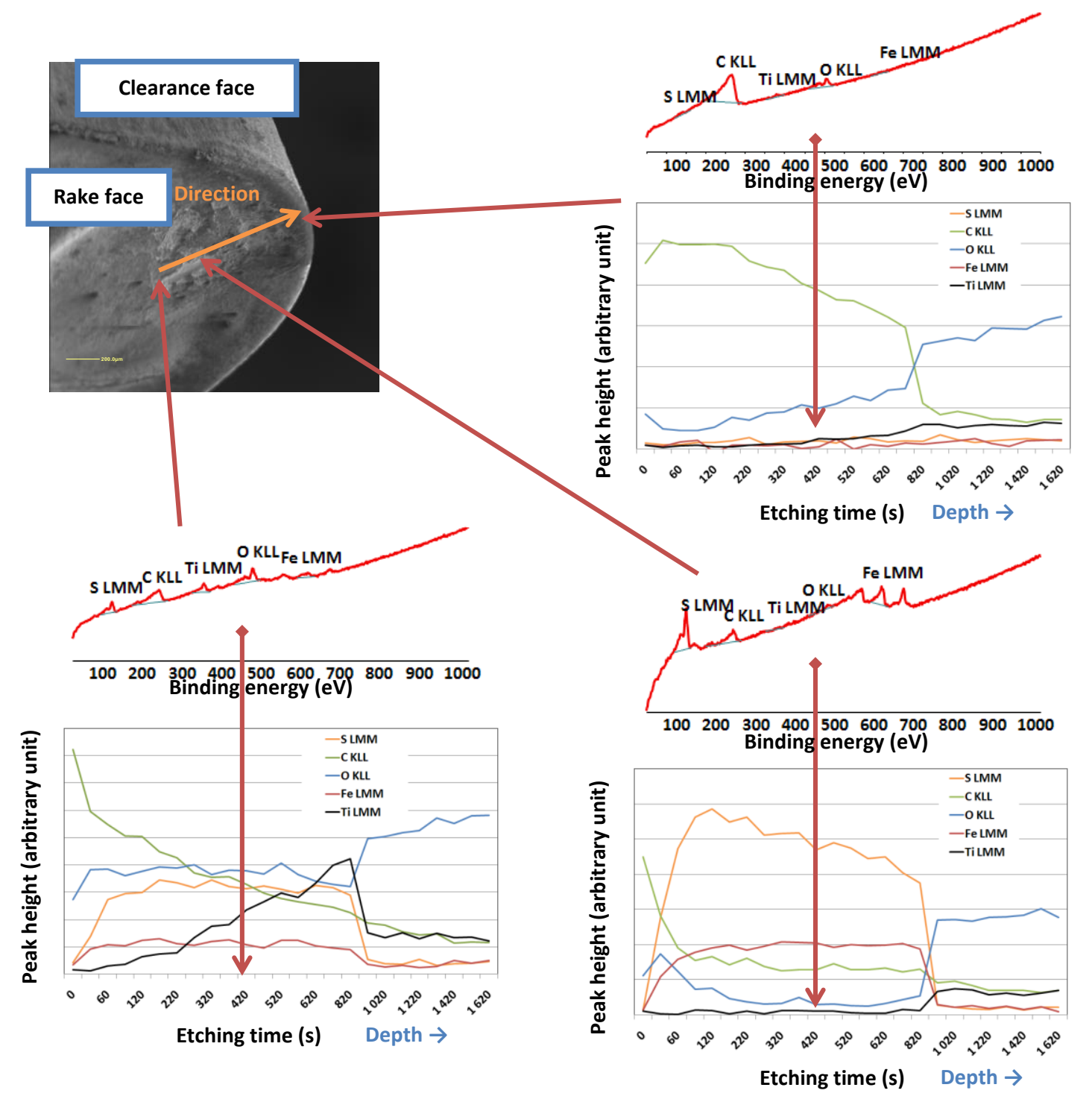

Fig. 6 


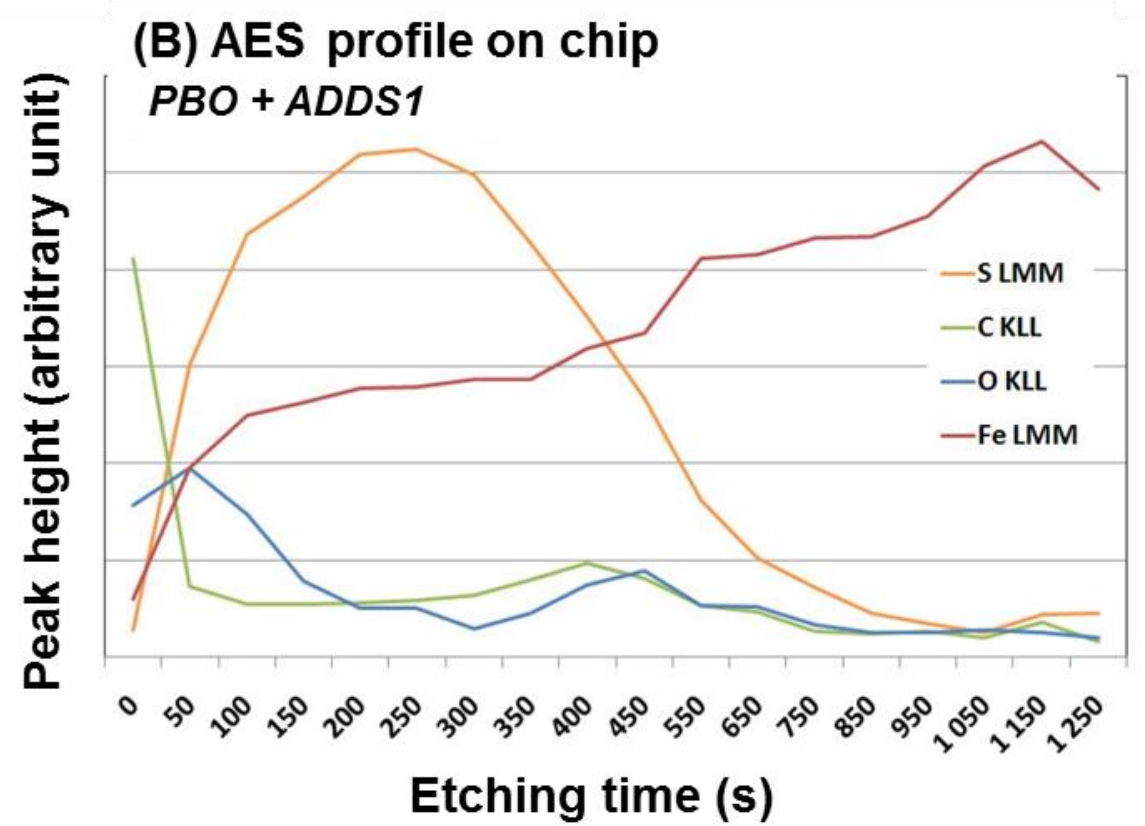

Fig. 7 


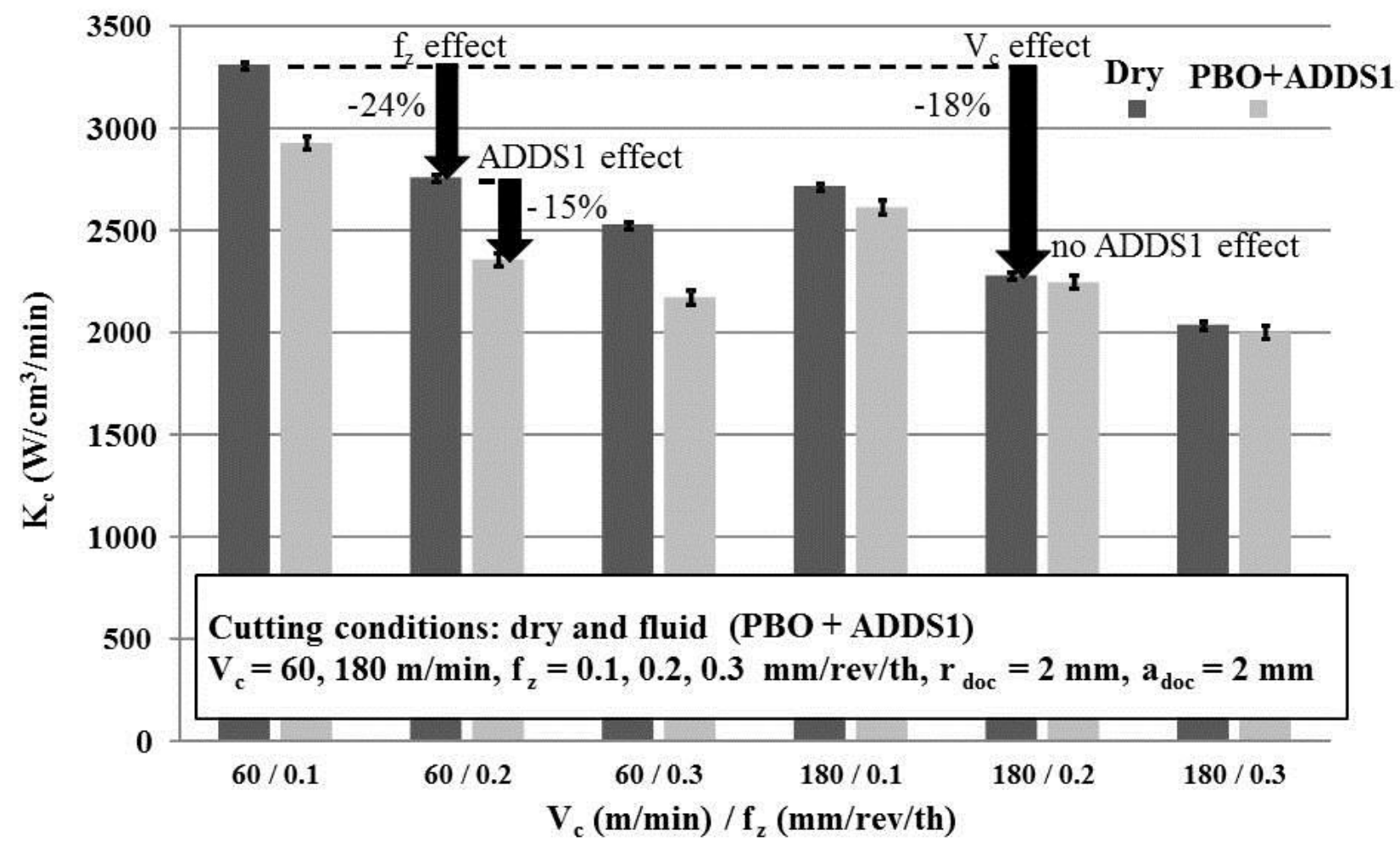

Fig. 8(A) 


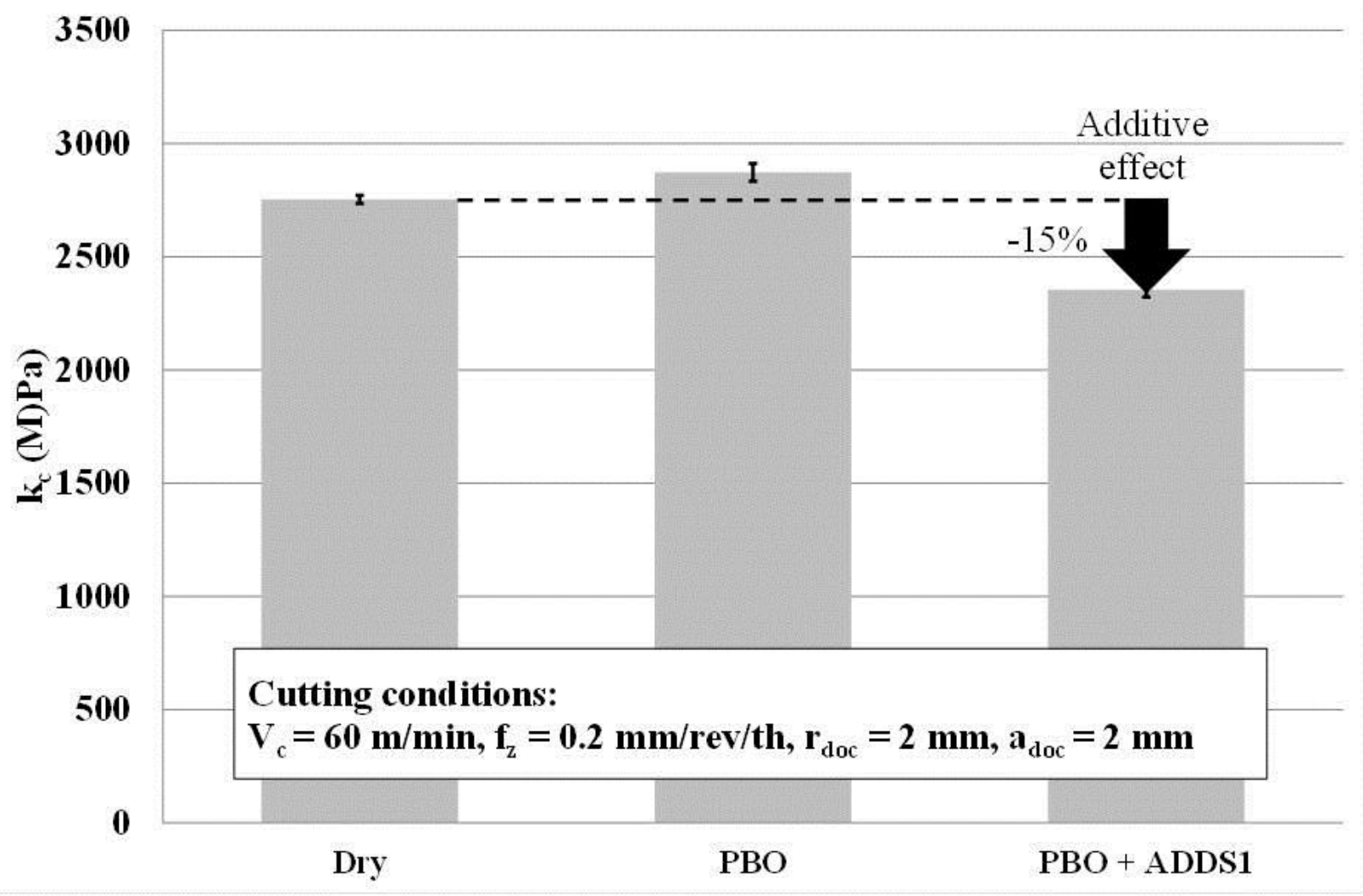

Fig. 8(B) 


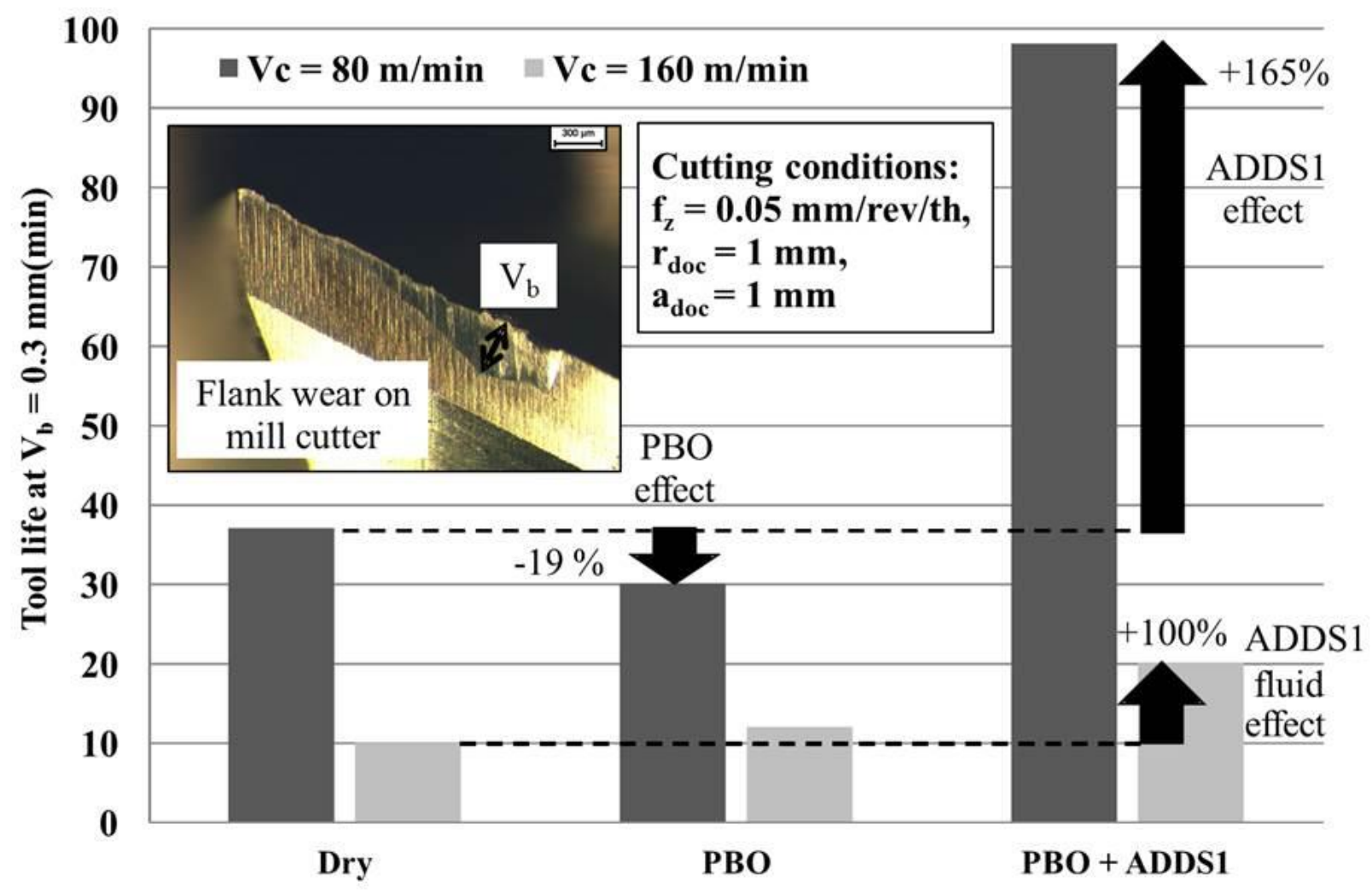

Fig. $8(\mathrm{C})$ 


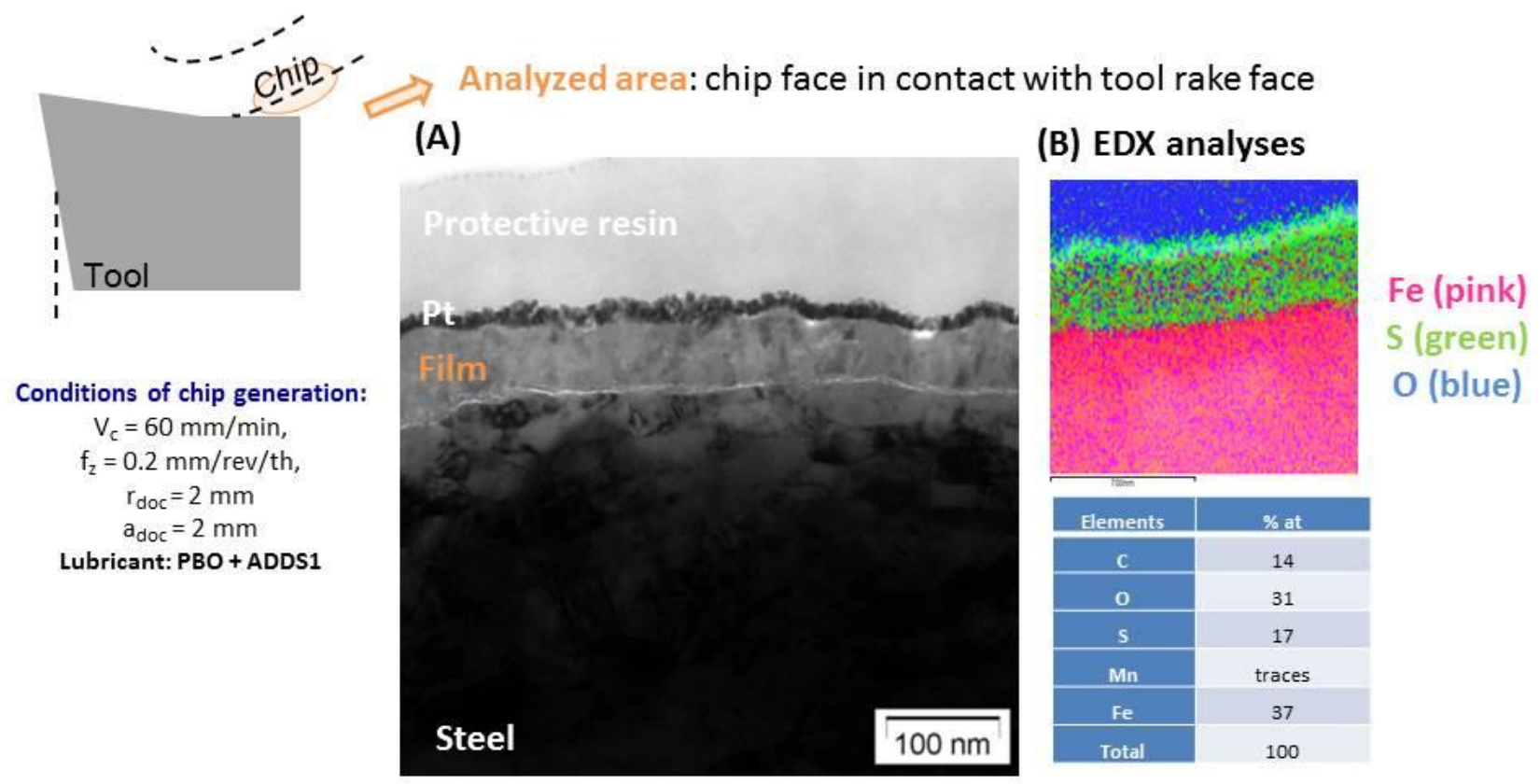

Fig. 9 


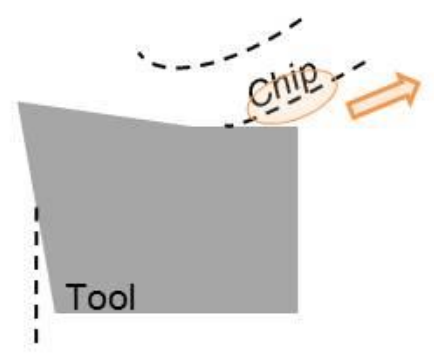

(a) AES depth profile:

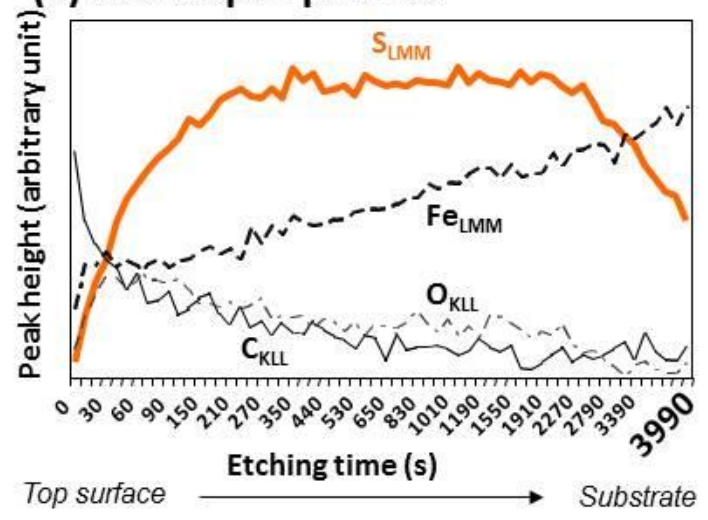

Analyzed area: chip face in contact with tool rake face

Conditions of chip generation:

$V_{c}=60 \mathrm{~mm} / \mathrm{min}, f_{z}=0.2 \mathrm{~mm} / \mathrm{rev} / \mathrm{th}$,

$$
r_{\text {doc }}=2 \mathrm{~mm} \text { and } a_{\text {doc }}=2 \mathrm{~mm}
$$

Lubricant: PBO + ADDS1

(b) XPS $-S_{2 p}$ peak:

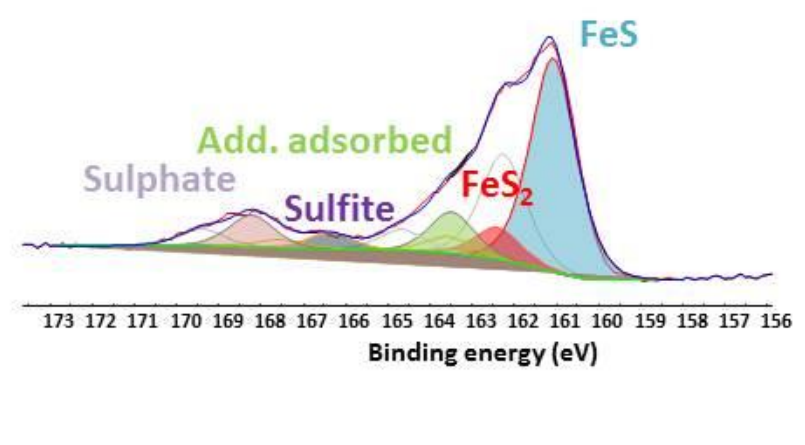

Fig. 10 


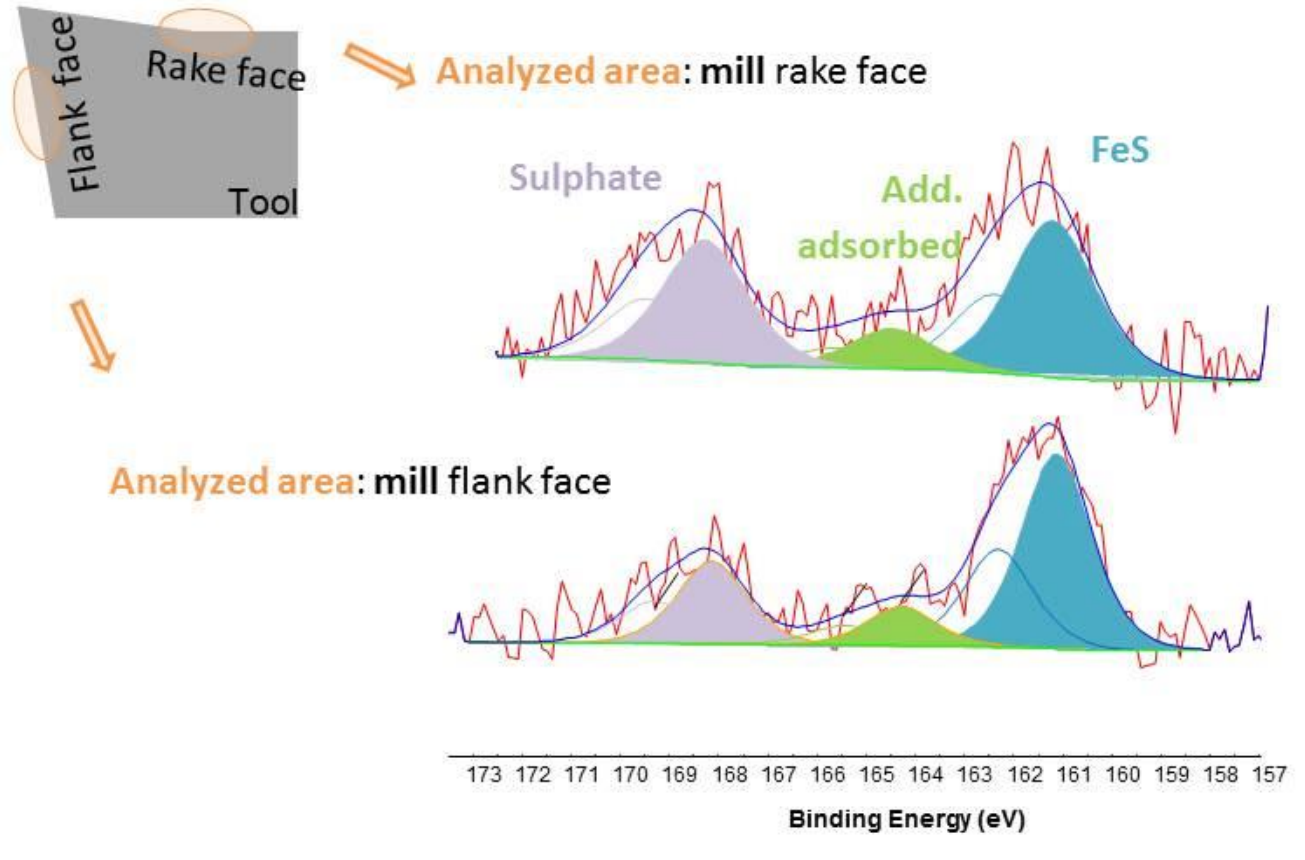

Fig. 11 
(A) $500^{\circ} \mathrm{C}-\mathrm{UHV}$

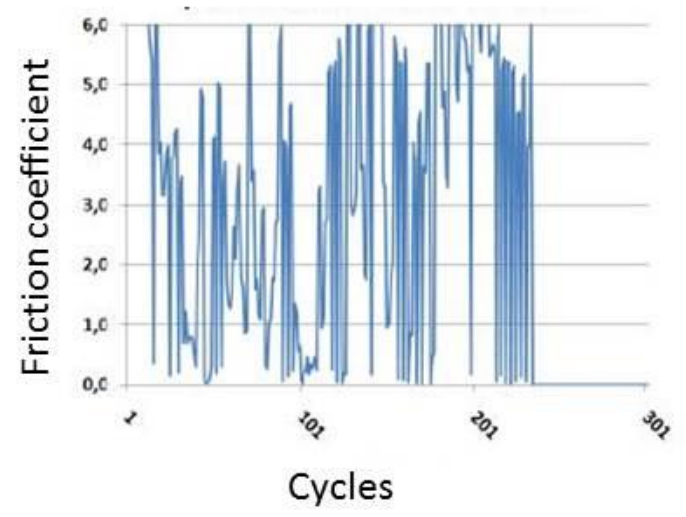

(B) $500^{\circ} \mathrm{C}-10^{-1} \mathrm{mbar}$ pentasulfide (ADDS1) $\left.R_{1}-s+\right]_{n=5} R_{2}$

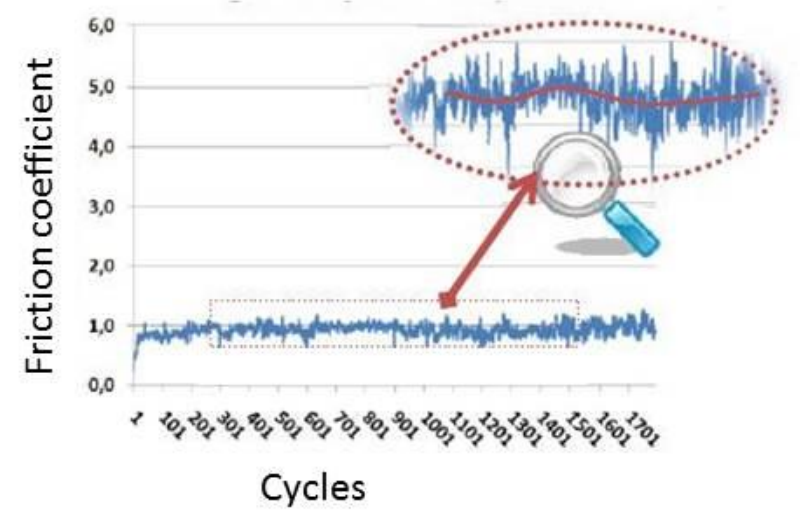

Fig. 12 


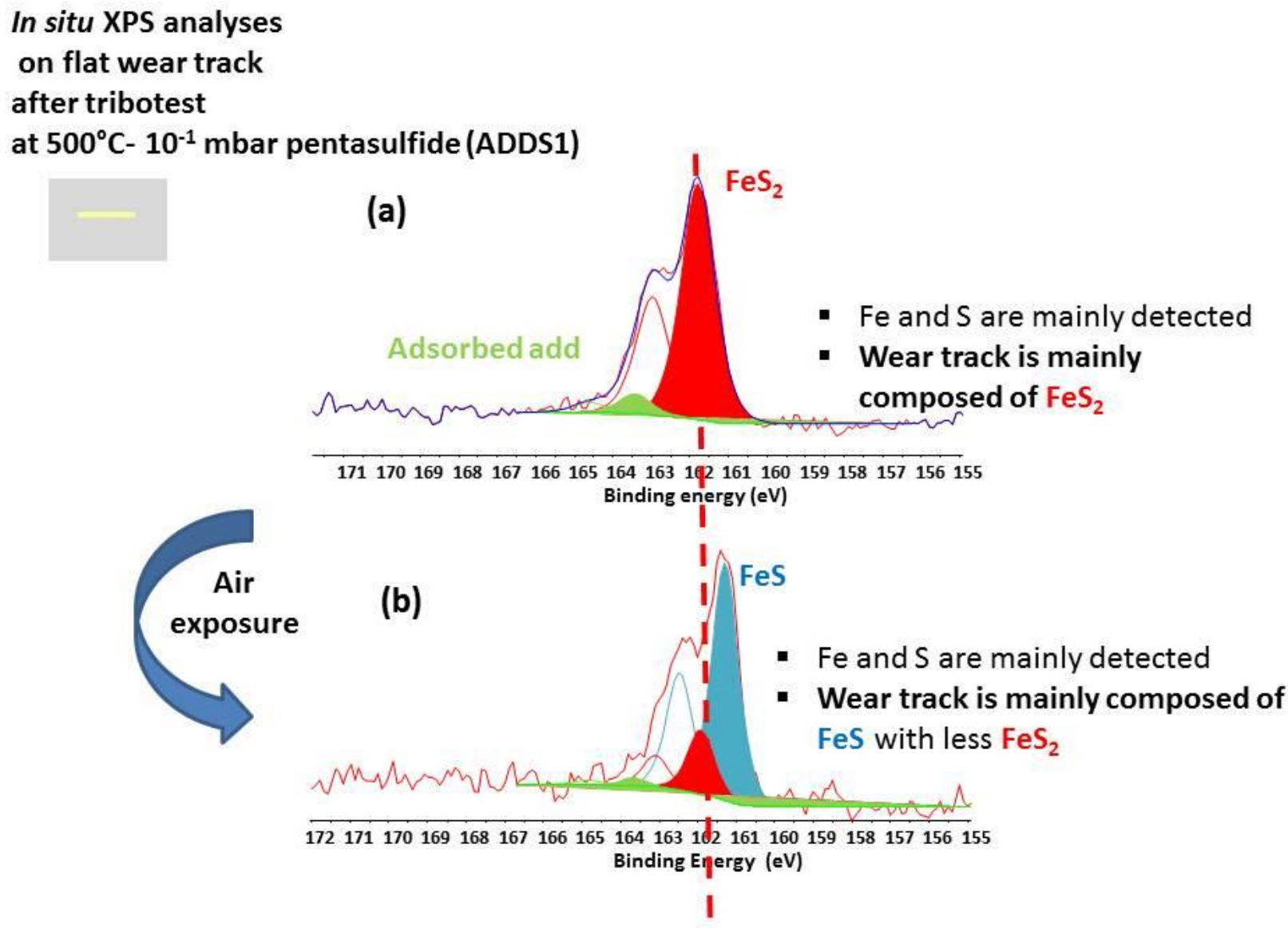

Fig. 13 


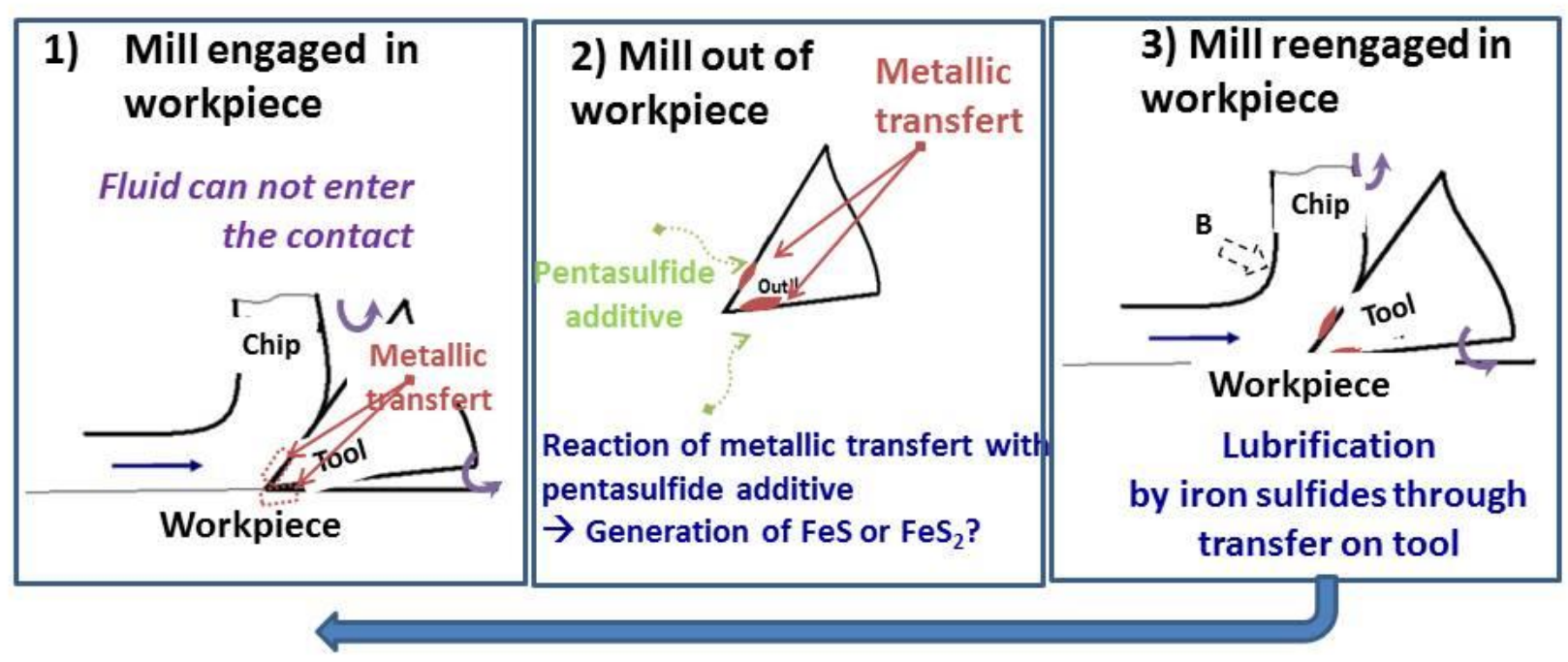

Fig. 14 